Miraglia, M., \& Johns, G. (2015, November 9). Going to Work Ill: A Meta-analysis of the Correlates of Presenteeism and a Dual-path Model. Journal of Occupational Health Psychology. Advance online publication. http://dx.doi.org/10.1037/ocp0000015

'This article may not exactly replicate the final version published in the APA journal. It is not the copy of record.'

\author{
Going to Work Ill: A Meta-analysis of the Correlates of \\ Presenteeism and a Dual-path Model
}

\author{
Mariella Miraglia ${ }^{1}$ and Gary Johns ${ }^{2}$ \\ Norwich Business School, Norwich, UK \\ Concordia University, Montreal, Quebec, Canada
}

Author Note

${ }^{1}$ Thomas Paine Study Centre, Norwich Business School, University of East Anglia, NR4

7TJ, Norwich, Norfolk, UK. +44 (0) 6103 593487; m.miraglia@uea.ac.uk

${ }^{2}$ Department of Management, John Molson School of Business, Concordia University, 1455 de Maisonneuve Blvd. West, Montreal QC H3G 1M8, Canada. gary.johns@ concordia.ca 


\begin{abstract}
Interest in presenteeism, attending work while ill, has flourished in light of its consequences for individual well-being and organizational productivity. Our goal was to identify its most significant causes and correlates by quantitatively summarizing the extant research. Additionally, we built an empirical model of some key correlates and compared the etiology of presenteeism versus absenteeism. We used meta-analysis (in total, $K=109$ samples, $N=175,965$ ) to investigate the correlates of presenteeism and meta-analytic structural equation modeling to test the empirical model. Salient correlates of working while ill included general ill health, constraints on absenteeism (e.g., strict absence policies, job insecurity), elevated job demands and felt stress, lack of job and personal resources (e.g., low support and low optimism), negative relational experiences (e.g., perceived discrimination), and positive attitudes (satisfaction, engagement, commitment). Moreover, our dual process model clarified how job demands and job and personal resources elicit presenteeism via both health impairment and motivational paths, and they explained more variation in presenteeism than absenteeism. The study sheds light on the controversial act of presenteeism, uncovering both positive and negative underlying mechanisms. The greater variance explained in presenteeism as opposed to absenteeism underlines the opportunities for researchers to meaningfully investigate the behavior and for organizations to manage it.
\end{abstract}

Keywords: presenteeism; absenteeism; meta-analysis; health; demands. 


\section{Going to Work Ill: A Meta-analysis of the Correlates of \\ Presenteeism and a Dual-path Model}

While absenteeism from work has a venerable research history, interest in presenteeism is a fairly recent development. Although the term presentee was evidently coined many years ago by Mark Twain (1892), it remained until the late 1990s for scholarly interest in the concept of presenteeism to emerge. In this paper, we present the first meta-analysis of the correlates of the act of presenteeism, build an empirical model of some key correlates, and compare and contrast the ostensible etiology of absenteeism versus presenteeism. Our goal is to summarize what is currently known about the act of presenteeism and thus provide a sense of direction for future research on this important phenomenon.

The term presenteeism has been used in several ways in the literature over the years, and Johns (2010) reviewed nine distinct definitions of the concept (see also Wężyk \& Merecz, 2013). However, recent scholarly treatment has converged on two main definitions. The first of these is attending work while ill (Aronsson, Gustafsson, \& Dallner, 2000). The second definition, which dominates the occupational medicine literature, is productivity loss stemming from attending while ill (Turpin et al., 2004). Although affirming the importance of the latter phenomenon, Johns $(2010,2012)$ questioned this definition for conflating cause with effect and pre-empting the study of the causes of going to work ill. In the meta-analyses to be reported here we restrict the purview to the causes and correlates of the act of presenteeism-going to work ill. Most research on productivity loss has concentrated on its association with various medical conditions.

Perhaps the most interesting thing about presenteeism is that it represents a muchoccupied but only recently studied state between being absent (and ostensibly exhibiting no productivity) and fully productive work engagement. Presentees will vary in their productivity due to a host of personal and contextual circumstances, such as the exact nature of their health 
problems. Nonetheless, they are unlikely to be fully engaged and fully productive. Hence, the causes and correlates of being in this "gray area" are of considerable interest. One motive to better understand presenteeism arises from its contradictory consequences for individuals and organizations. In the literature, presenteeism has been associated with both negative and positive effects on employee productivity and welfare. Our research was designed to probe and resolve this contradiction.

Working while sick has been repeatedly found to account, in the aggregate, for much more productivity loss than absenteeism (e,g, Collins et al., 2005; Hemp, 2004). Moreover, Gustafsson and Marklund (2011) found that presenteeism was associated with subsequent health decline and that it presaged elevated absenteeism. Lu, Lin, and Cooper (2013) found that it had deleterious effects on subsequent mental and physical health, exhaustion, and job satisfaction. Thus, working while ill can compound the effects of the initial illness and also result in negative job attitudes and withdrawal from work. Issues of contagion (Fidelman, 2009) and workplace safety are also of concern. While absentees are effectively quarantined, presentees might infect an entire office or clinic (Widera, Chang, \& Chen, 2010), contaminate consumer food products (Hopkins, 2014), or be distracted into committing serious errors or safety violations (Niven \& Ciborowska, 2015).

However, we need not harbor such a negative view of presenteeism (Johns, 2010; Wężyk \& Merecz, 2013). Some productivity is better than no productivity, especially when the illness in question is neither debilitating nor contagious, and going to work and making some contribution might be self-affirming for some sufferers of chronic illnesses such as migraine or depression (Johansen, Aronsson, \& Marklund, 2014; Roe \& van Diepen, 2011). In addition, despite lowered productivity, attendance in the face of non-contagious illness might be seen as an example of organizational citizenship behavior or signal the kind of commitment that can turn a temporary 
position into a permanent one (cf. Snir \& Harpaz, 2012). All in all, both the negative and positive consequences suggest the value of summarizing the causes and correlates of presenteeism. More importantly, this article attempts to integrate the apparently contrasting views (i.e., negative and positive) of working when sick by suggesting a model which links presenteeism to its determinants through a dual pathway. The dual-path model addresses some of the contradictions in the etiology of presenteeism.

\section{Perspectives on Presenteeism}

In the following sections, hypotheses are offered that specify the expected effects of various correlates of presenteeism. The behavior ultimately has to do with the decision to go to work or be absent when ill, and the performance consequences of this decision have been of fundamental interest in the extant literature. Thus, we commence by hypothesizing the likely relationships between presenteeism and health, absenteeism, and job performance. Then, to organize the many other correlates and causes of presenteeism, a mediated model is offered (Figure 1) in which contextual and personal variables are related to the acts of presence versus absence both directly and indirectly through health impairment and attitudinal/motivational paths. The model draws explicitly on the demand-control-support model (DCS; Johnson \& Hall, 1988; Johnson, Hall \& Theorell, 1989; Karasek, 1979; Karasek \& Theorell, 1990), the job demands-resources framework (JD-R, Bakker et al., 2014), and the substitution hypothesis (Caverley et al., 2007). In addition, it follows the spirit of models by Aronsson and Gustafsson (2005) and Johns (2010) that specify both contextual and personal antecedents of presenteeism. It was expected that presenteeism may originate from both a decline in health, following a negative strain path, and elevated motivation, deriving from positive job attitudes. Thus, work and personal characteristics would exhibit differential indirect effects on working while ill, depending on the interplay between the health impairment and attitudinal/motivational paths. 
The model offers a guide to the formulation of hypotheses for the relationships of constraints on absenteeism, job demands, and job and personal resources with attending work when sick. Hence, the expected direct links are presented first. Then, acknowledging the presence of the double path in mediating the associations between those variables and presenteeism, some paradoxes and competing hypotheses are clarified.

\section{Presenteeism and Health, Absence, and Performance}

Given that presenteeism is defined as attending work while ill, it might be expected that sicker people are more at risk for the behavior, and such a finding would be a basic construct validity requirement. However, it is probable that some are illnesses are seen as more or less legitimate causes to be absent, with the latter provoking more presenteeism. In particular, there is specific cross-cultural evidence that depression is viewed as a less than fully appropriate reason to be absent (Johns \& Xie, 1998). In fact, depression -- and psychological problems in general -may be more difficult to disclose in the workplace, since they may be perceived particularly negatively given the well documented stigma of mental and emotional illness (Corrigan, 2005; Hinshaw, 2007). Additionally, calling in sick because of depression might be avoided because it may be associated with a lack of self-control, and employees may also underrate the import of psychosomatic health complaints (Johns \& Xie, 1998). Thus, it was expected that depression and psychological problems would be especially associated with presenteeism. Such conditions have been particularly implicated in productivity loss among presentees (Johns, 2010), and this may stem from the reluctance of even the seriously depressed to miss work compared to those with physical ailments.

Hypothesis 1: a) Those in poorer general health will exhibit more presenteeism and b) the health-presenteeism relationship will be stronger in the case of mental health and depression than in the case of general health. 
How should presenteeism relate to absenteeism and performance? At the level of discrete illness events, within-person, absenteeism and presenteeism would be negatively correlated. However, in a between-person sense, people who are in poorer health should in general exhibit both higher absence and presence, as their risk for both behaviors increases. Although certain constraints on absence might prompt increased presenteeism (see below), a positive relationship is still expected to hold. A negative relationship is expected between presenteeism and global performance and a positive relationship is expected with productivity loss due to illness. Illness should sap energy and divert attention such that personal productivity suffers and performance ratings are negatively affected. Although some presentees might be viewed as "good soldiers" engaging in organizational citizenship behavior, it is expected that this will not overcome decrements in in-role performance due to illness.

Hypothesis 2: Presenteeism will be positively related to a) absenteeism and b) productivity loss due to poor health and c) negatively related to global performance ratings.

Although the preceding hypothesis does not make the distinction, productivity loss may be a more sensitive criterion for presenteeism than global rated performance. Productivity loss refers specifically to the presence of illness and has a within-person referent. Global performance basically reflects between-person distinctions. Thus, an excellent performer who loses productivity due to illness might still be one of the best in her work unit (Johns, 2012).

\section{Constraints on Absenteeism}

According to the substitution hypothesis (Caverley, Cunningham, \& MacGregor, 2007) one source of presenteeism occurs when employees are constrained from engaging in absenteeism. That is, if absence in response to sickness is a less available option, employees will resort to coming to work ill, substituting presence for absence. Such constraints on absence might be more or less direct, and they might emanate from either the employer or the employee. 
We consider organizational policies, job insecurity, personal financial difficulties, and difficulty of replacement as possible constraints on absenteeism, resulting in presenteeism.

Formal or informal pressure to attend work that is inherent in organizational practices and policies constitutes the most direct constraint on absenteeism. Organizations vary considerably in the extent to which they monitor attendance, punish absence, and grant sick leave, and such control policies are among the strongest negative correlates of absenteeism (Farrell \& Stamm, 1988; Johns, 2008). Given this, presenteeism should be highest when organizational constraints against absenteeism are high. A second variable with implications for attending while ill is the extent of replacement available when the employee is absent (Aronsson et al., 2000; McKevitt, Morgan, Dundas, \& Holland, 1997). Individuals who cannot be replaced, for instance due to unique qualifications, will be inclined to show up ill as work will simply accumulate while they are absent. Another salient constraint against absenteeism is job insecurity. Absence has a very well established negative relationship with unemployment rate (e.g., Shoss \& Penny, 2012) and a positive relationship with union membership (e.g., Mastekaasa, 2013), and both effects have been attributed to underlying variations in job security. Despite illness, the insecure may be motivated to show up so as not to incur discipline or dismissal. One source of insecurity is impermanent and contingent work. Although some may prefer such work, it is generally thought to be a source of insecurity, and it has repeatedly been shown to be associated with reduced absenteeism (Johns, 2010), an effect that has often been inferred as signaling presenteeism by those desirous of earning permanent status. A final constraint against absenteeism is personal financial difficulties (Aronsson \& Gustafsson, 2005). Those in the lowest paying jobs are least likely to have access to fair sick pay, and those in financial straits will be disinclined to incur disapproval for absence. 
Hypothesis 3. Given their likely constraints on absenteeism, it is expected that a) stricter absence policies, b) job insecurity, c) impermanent employment, and d) personal financial difficulties will be positively related to presenteeism, while e) ease of replacement will be negatively related to it.

\section{Job Demands and Experienced Stress}

Job demands are physical, social, and organizational features of work requiring physical or mental effort and provoking physiological or psychological costs (Bakker, Demerouti, \& Sanz-Vergel, 2014). To organize a range of distinct variables, we group these into role demands, time demands, and global or overall demands. Role demands include role ambiguity and conflict, physical demands, heavy workload, difficult patients or clients, understaffing, and supervisory duties. Time demands include overtime work, shift work, time pressure, and long hours. Overall demands pertain to global measures or omnibus "work pressure." Some of the most replicated findings in organizational behavior include the positive association between job demands and stress and burnout (Crawford, LePine, \& Rich, 2010; Schaufeli \& Taris, 2014) and between stress and poor health (Ganster \& Rosen, 2013).

On first consideration, attending work while ill might seem counter-indicated by a very demanding job. After all, who likes to expend physical or mental effort while suffering medically? However, it can be predicted that, speaking generally, job demands will be positively associated with presenteeism. This follows from the documented connection between many discrete job demands and ill health, or to felt stress and burnout, which have been shown to negatively affect health. For example, heavy workload (Bowling \& Kirkendall, 2012; Pohling, Buruck, Jungbauer, \& Leiter, in press), long work hours (Ng \& Feldman, 2008; Sparks, Cooper, Fried \& Shirom, 1997), shift work (Wang et al., 2014), and overtime work (Caruso, Hitchcock, 
Dick, Russo, \& Schmit, 2004) are all associated with impaired health. In terms of the abovementioned dual-path model, this logic is depicted by the health impairment path.

A positive association with demands also follows from Hobfoll's (2001) conservation of resources theory: to avoid any possible resource losses caused by job demands, employees will capitalize on other available resources, including continuing to work when sick (Demerouti, Le Blanc, Bakker, Schaufeli, \& Hox, 2009).

Negative health impact stems from both hindrance and challenge demands (LePine, Podsakoff, \& LePine, 2005), although the latter (e.g., high workload, supervisory responsibility) might additionally prompt presenteeism via engagement (Crawford et al., 2010) and positive motives to attend (see below). Furthermore, implicit or explicit in many high demand jobs are rigorous expectations for attendance. That is, the very contextual factors that increase job demands also put a premium on good attendance.

Hypothesis 4: Presenteeism will be positively related to a) role demands, b) time demands, c) overall job demands, d) experienced stress, and e) burnout.

Experiencing illness, the choice between absenteeism or presenteeism would seem to be a particularly personal and individual decision. However, Johns (2011) has pointed out that both behaviors can be used strategically to fulfill perceived social obligations and manage one's social adjustment in the workplace. Also, presenteeism would seem to be susceptible to the same kind of social influence that has been well documented for absenteeism (e.g., Addae, Johns, \& Boies, 2013; Dello Russo, Miraglia, Borgogni, \& Johns, 2012; Diestel, Wegge, \& Schmidt, 2014). Thus, we considered negative relational experiences in the workplace and work-family conflict as relational demands which can influence the decision to show up or be absent when ill. Negative relational experiences in the workplace include discrimination, harassment, and abuse. As noted for job demands, these experiences would not at first seem conducive to motivating 
attendance while ill, since they could have a negative impact on the attitudinal/motivational mechanism of the dual-path model. Such negative episodes may damage job attitudes and motivation as well as felt obligation to attend, discouraging presenteeism. However, such threats can provoke felt stress and illness (Bowling \& Beehr, 2006; O’Leary-Kelly, Bowes-Sperry, Bates, \& Lean, 2009; Willness, Steel, \& Lee, 2007) and, consequently, incite the behavior of working when sick via the health impairment path. Additionally, negative relational experiences often occur in the context of asymmetrical power relationships that signify low control for the victim. Thus, they are prone to be positively connected to presenteeism.

Hypothesis 5: Presenteeism will be positively related to a) perceived discrimination, b) harassment, and c) abuse.

Work-family conflict may be seen as a factor co-varying with presenteeism, since the two might reciprocally trigger each other. Differently from other demands, work-family conflict involves people and relationships within one's more general life context, rather than work colleagues, supervisors, or clients, that can influence attendance dynamics and at the same time be influenced by the decision to attend work or be absent when ill.

People experiencing elevated work to family conflict would seem prone to fall prey to presenteeism. That is, any source of high obligation to work (positively or negatively motivated) should both cause conflict with family obligations and necessitate attendance when ill. Work to family conflict may be indicative of a highly demanding job (Frone, Yardley, \& Markel, 1997; Mostert, 2009; Van der Heijden, Demerouti, Bakker, \& The NEXT Study Group, 2008), which may require working longer hours, working on weekends, and taking work home, reducing time for family and pushing people to use any occasion to be at work (Parasuraman \& Simmers, 2001), regardless of state of health. Moreover, working while ill may preclude employees from fully recovering after illness and force them to use home time to restore physical and mental 
energies (Demerouti, Bakker, \& Bulters, 2004; Geurts, Kompier, Roxburgh, \& Houtman, 2003), neglecting family responsibilities and, consequently, exacerbating work-family conflict.

On the other hand, people whose family life already interferes with work would be disinclined to find reasons to attend when ill. Family to work conflict is more responsible for employees' absenteeism than work to family interference, because individuals are more likely to use days off to solve family-related problems (Kossek \& Ozeki, 1999). This type of conflict likely reflects heavy home demands, which drain physical and psychological resources (Mostert, 2009; Ross, Mirowsky, \& Goldsteen, 1990; ten Brummelhuis, Haar, \& Van der Lippe, 2010) and diminish work motivation (ten Brummelhuis, Ter Hoeven, De Jong, \& Peper, 2013), decreasing the likelihood to attend work if sick.

Hypothesis 6: Presenteeism will be a) positively related to work to family conflict and b) negatively related to family to work conflict.

\section{Job and Personal Resources}

Job resources are aspects of work that support goal achievement, enhance personal and professional growth, and aid coping with job demands (Bakker et al., 2014). Among the resources that might offset job demands and resultant stress and burnout (Park, Jacob, Wagner, \& Baiden, 2014), job control has figured in presenteeism research. Most broadly, control consists of the ability to influence what happens on the job. We suggest a negative relationship between control and presenteeism. This reflects the definition of job resources and, more specifically, the capacity of job control to offset demands and associated physiological and psychological costs, such as strain and exhaustion, which are factors that trigger presenteeism (H4). Even more directly, people who are "in control" are less likely to feel pressure to attend when ill. Furthermore, a resourceful work environment, such as one characterized by high levels of 
control, may work through the health mechanism of the dual-path model. Job control reduces health ailments, consequently decreasing the necessity for presenteeism.

Hypothesis 7: Presenteeism is negatively related to job control.

Another resource pertinent to presenteeism is knowing that one is engaged in significant or meaningful work. However, this resource is likely to stimulate presenteeism. The significance of work is to some extent socially constructed and reflected both in population stereotypes and professional canon. It is often based on the perceived impact of work on others, such as students, patients, or clients (Grant, 2008; Humphrey, Nahrgang, \& Morgeson, 2007). Early interest in this variable was sparked by findings that presenteeism was elevated in the helping and caring professions (Aronsson et al., 2000; McKevitt et al., 1997). For instance, doctors and nurses may feel morally obligated to attend to their patients in accordance with their professional norms, but at the same time engage in self-treatment practices, making it difficult to assume a sick role (Christie \& Ingstad, 1996; McKevitt et al., 1997; Senden, Løvseth, Schenck-Gustafsson, \& Fridner, 2013) and promoting a low sense of self-care (Crout, Chang, \& Cioffi, 2005). Knowing that one's work matters might prompt attendance in the face of medical discomfort, especially given that meaningful work ameliorates felt stress (Glazer, Kozusznik, Meyers, \& Ganai, 2014). Hypothesis 8: Presenteeism is positively related to work or job significance.

A supportive workplace may represent a further relevant resource for employees, giving them the confidence needed to avail themselves of time off from work to recuperate from illness or prevent a worsening of their condition. Supportive colleagues, supportive supervision, a supportive organization, and more general high quality leadership should thus be associated with less presenteeism. Among other factors, a supportive environment will encourage self-disclosure of illness (Munir, Leka, \& Griffiths, 2005) and clarify its occasional incompatibility with work. 
It may also facilitate provisions for adjustment and backup so as to reduce perceived pressure to attend when ill.

Hypothesis 9: Presenteeism will be negatively related to a) collegial support, b) supervisory support, c) organizational support, and d) quality leadership.

Personal resources are individual characteristics associated with resiliency and the inclination to effectively influence the work context (Shaufeli \& Taris, 2014). Personal resources presented in the literature include optimism, self-efficacy, and self-esteem (e.g., Xanthopoulou, Bakker, Demerouti, \& Schaufeli, 2009). However, as the present meta-analysis is limited by what has been already studied in the presenteeism literature, we focused on optimism and conscientiousness as examples of personal resources.

People with a generally optimistic outlook experience more vigour, dedication, and absorption in their jobs (Xanthopoulou et al., 2009), which should increase their resolve to attend even if not in perfect health. Also, conscientiousness can be included among personal resources, since its key facets include dependability (Goldberg, 1990) and resilience (Barrick \& Mount, 1991). Conscientious employees are dependable, responsible, determined, and resolute (Barrick \& Mount, 1991; Digman, 1990), so they would be expected to make the extra effort to show up in the face of health limitations. As personal resources, these characteristics support work goal accomplishment, countervail job demands, and forestall self-pity in the face of discomfort (Shaufeli \& Taris, 2014).

Hypothesis 10: Presenteeism will be positively related to a) optimism, and b) conscientiousness.

\section{Job Attitudes and Justice}

The impact of job attitudes and organizational justice on presenteeism implicates the "want to" rather than the "have to" aspect of the behavior. Liking one's job, being affectively 
committed to the organization, being work-engaged, and feeling justly treated are states that should motivate good attendance even in the face of some medical discomfort. Each of these positive affective states has been shown to foster organizational citizenship behavior (Dalal, Baysinger, Brummel, \& LeBreton, 2012; Hoffman, Blair, Meriac, \& Woehr, 2007), and some presenteeism can be viewed as exemplary of such behavior (Johns, 2010). Furthermore, these same positive reactions to the workplace have been associated with good health and well-being (e.g., Ford \& Huang, 2014; Meyer, Maltin, \& Thai, 2012; Robbins, Ford, \& Tetrick, 2012; Schaufeli \& Taris, 2014), which might make people feel "well enough" to attend. Together, these factors suggest that positive feelings toward work should stimulate presenteeism.

Hypothesis 11: Presenteeism will be positively related to a) job satisfaction, b) affective commitment, c) work engagement, and d) organizational justice.

Finally, although we offer no specific hypotheses, we were interested to see how gender related to presenteeism. Compared to men, women are at greater risk for many chronic illnesses (Clough, 2011; Rodin \& Ickovics, 1990). In line with H1a, this suggests more inclination toward presenteeism. However, women engage in more health-protective behaviors (Nelson \& Burke, 2002), and they tend to be absent from work more than men (Côté \& Haccoun, 1991; Patton \& Johns, 2011, 2012). In combination, these behaviors might reveal a disinclination to attend when ill and thus exacerbate health problems. We were also interested to see if those in public sector jobs exhibited more or less presenteeism than those in private sector jobs. Public jobs often offer more job security, a factor that should to some extent preclude presenteeism. However, especially in the samples we synthesize (many European), many public sectors jobs are in the caring and helping professions, and this might stimulate presenteeism due to work significance or felt professional obligations.

\section{The Dual-path Model: Indirect Effects}


Before introducing the indirect links, it is important to note that our model is limited by both the requirement for a sufficient $K$ (total number of samples for the meta-analytic correlation) and $N$ (total sample size across samples) for its constituent variables and the need for parsimony. Hence, for example, we relied on job satisfaction as representative of an attitudinal/motivational path to presenteeism and restricted the choice of demands and control to overall summary measures as opposed to facets. As demands, control, and resources were expected to initiate presenteeism through a double pathway, the direction of the indirect relationships between them and presenteeism would vary depending on the followed path.

Job demands should relate negatively and indirectly to working when ill via the motivational path, due to their negative effect on intrinsic motivation (LePine et al., 2005; Tetrick, Slack, Da Silva, \& Sinclair, 2000) and job attitudes (Luchman \& González-Morales, 2013; van der Doef \& Maes, 1999), which, in turn, are thought to correlate positively with presenteeism (H11). On the other hand, job demands might trigger presenteeism via the health impairment path, since they result in elevated stress and medical problems (Johnson et al., 1989; Bakker et al., 2014), increasing the probability of working when ill (Pohling et al., in press). Also, constraints on absenteeism represent context-related (i.e., job insecurity) and personrelated (i.e., personal financial difficulties) demands for presence (Aronsson \& Gustafsson, 2005; Johns, 2010), and are thus expected to play an analogous role to job demands, exhibiting the same indirect relationships.

Moreover, following the health process, we expected job control and supervisory/collegial support to be indirectly associated with lower presenteeism, because such job resources can reduce experienced stress, burnout, and health risk (Bakker, Demerouti, \& Euwema, 2005; Johnson et al., 1989; Schaufeli \& Bakker, 2004). However, control and support might stimulate presenteeism motivationally, since they facilitate positive attitudes, motivation, 
and dedication to the job (Bakker \& Demerouti, 2006; Crawford et al., 2010). As discussed earlier, positive dispositional traits, such as optimism, denote personal resources, reducing strain and thus enhancing health, job attitudes, vigor, and task dedication (Schaufeli \& Taris, 2014; Xanthopoulou et al., 2009). Accordingly, they would exhibit a positive indirect link with presenteeism via the motivational path, and a negative indirect effect via health.

\section{Method}

\section{The Meta-analytic Databases}

To locate primary studies for the meta-analysis we searched Google Scholar, PsychInfo, MedLine, Web of Science, ProQuest Business, and Business Source Complete using the keywords presenteeism, sickness presence, and sickness attendance (Johns, 2012). Also, we conducted a manual search of the reference lists of relevant articles. Moreover, to obtain unpublished contributions we searched ProQuest Dissertation and Thesis, and we were also able to access unpublished presenteeism data from a broad longitudinal survey that has underpinned several published articles (e.g., Dello Russo et al., 2013). Finally, we accessed the database for the fifth European Working Conditions Survey (EWCS), downloaded from the UK Data Service archive. The EWCS was conducted by the European Foundation for the Improvement of Living and Working Conditions in collaboration with Gallup Europe in 2010, sampling a total of 43,816 employees from 34 countries (the 28 European Union nations plus Macedonia, Turkey, Norway, Albania, Kosovo, and Montenegro). The average EWCS sample was 1,289, ranging from 1000 to 4001 .

In total, 313 studies were identified. Studies were considered for subsequent analysis if they directly or indirectly operationalized presenteeism as going to work when ill, reported useful statistics regarding relationships with correlates, and contained no data already employed in other articles (e.g., did not use the EWCS database). When data were reported separately by 
gender or for grouped years of tenure, they were averaged between or among the groups. If multi-year data were presented, they were averaged across years. In the case of interventions, only pre-test data were used. When several independent samples were presented, we coded these separately. Thus, the data for the 34 EWCS countries were treated as independent samples. Presenteeism was operationalized in one of three ways. Most common was a self-report of the number of days the respondent had attended work while ill over some designated time period, usually a year (e.g., "How many days did you go to work in the past six months even though you were sick or not feeling well?”, Johns, 2011). An alternative measure queried respondents on the subjective extent to which they had engaged in such behavior, using Likert or relative frequency response formats (e.g. "Has it happened over the previous 12 months that you have gone to work despite feeling that you really should have taken sick leave because of your state of health?", 1 = "No, never" to 4 = "Yes, more than 5 times, Aronsson et al., 2000). A few studies measured presenteeism indirectly as the correspondence between an individual's health condition (e.g., chronic disease, pain, disability) and his or her working status or sickness absenteeism rate. Thus, presentees were inferred to be those with poor health status who continued to work or did not exhibit absence. For example, participants were asked to describe the number and nature of illnesses experienced in the previous year and for each of them to state the number of sick days taken due to the illness in question (Bracewell et al., 2010). Workers who reported health complaints but no sickness absences were labeled as presentees.

We included all operationalizations in the general meta-analysis, but we systematically performed sensitivity analyses to gauge the effect of variations in measurement. This was especially important for the indirect measure, as it was employed with samples of chronically unhealthy people, in contrast to most primary studies. 
This screening process led to the retention of 109 independent samples $(N=175,965$ respondents) reported in 61 studies (52 journal articles or brief communications, 1 book chapter, 3 doctoral theses, 2 conference papers, 1 unpublished manuscript, unpublished data from the aforementioned longitudinal study, and the EWCS database).

Correlations $(r)$ were used to express effect sizes, since these were most often reported and can be computed from other statistics of association (Rosenthal \& DiMatteo, 2001). When primary studies did not include a correlation matrix authors were contacted. In all, 63 samples presented an $r$, and other reported statistics were converted to $r$. Thus, correlations were calculated from joint frequency distributions or $2 \mathrm{x} 2$ contingency tables using the formulas in Lipsey and Wilson (2001), or computed from chi square, as in Rosenthal and DiMatteo (2001). In a few cases they were obtained from reported means and standard deviations for presentees and non-presentees, utilizing the formulas in Borenstein, Hedges, Higgins, and Rothstein (2009). We also included two studies which provided only standardized regression coefficients, following the method in Peterson and Brown (2005). Additionally, we incorporated studies reporting odds ratios $(\mathrm{OR})$ or risk ratios (the latter were transformed into OR using the formula in Howell, 2006), in line with Darr and Johns (2008). Thus, we converted the log OR to $d$ and then to $r$ (Borenstein et al., 2009, pp. 47-48). Finally, for those studies using the indirect measure of presenteeism discussed above, correlations were calculated from either $2 \times 2$ tables, which crossed the correlates of presenteeism with the category non-presentee $(=0)$ or presentee $(=1)$ or means and standard deviations for non-presentees and presentees.

Having access to the EWCS survey database allowed us to calculate directly zero-order correlations between presenteeism and its correlates. The European survey measured presenteeism with two questions. First, respondents were asked to indicate whether they had worked when sick over the previous 12 months ("no," "yes," or "I was not sick"). A second 
question queried the number of days respondents had worked while ill. Those who were never sick $(n=5,170)$ were removed. Then, we coded "no" answers to the first question as zero presenteeism days, which we combined with the responses to question 2 (i.e., presenteeism days). A square root transformation was employed since the variable was positively skewed. For the same reason, a square root transformation was employed for absenteeism, measured as total sickness absence days in the previous year. Among the correlates, physical demands, time pressure, overall job demands, overall job control, participation, discrimination, harassment, abuse, quality of leadership, and optimism were assessed with multi-item scales, and alphas (calculated by us) ranged from .66 to .88. Other EWCS variables were measured with single items: job insecurity, role conflict and ambiguity, social support, job satisfaction.

The first author and a second rater (a doctoral student familiar with meta-analysis) coded the correlations between presenteeism and its correlates, the standardized regression coefficients, the odds and risk ratios, and the means for presentees and non-presentees. The data reported in joint frequency distributions, $2 \times 2$ contingency tables, and the EWCS were coded only by the first author, since in these cases, having access to the raw data, the effect sizes could be calculated directly. In total, 44 studies were double-coded, and interrater reliability coefficients were computed for the 48 presenteeism correlates reported in those studies. Interrater reliabilities ranged between .99 and 1.0.

\section{Meta-analytic Procedure}

In total, 100 meta-analyses of correlations were performed to examine the 55 correlates of presenteeism. The random effects procedure (Hunter \& Schmidt, 2004) was employed, correcting for sampling error and measurement error in presenteeism and using reliability artifact distributions to estimate the true population parameter. We first conducted a bare-bones metaanalysis of presenteeism reliability coefficients employing reliability generalization (Henson \& 
Thompson 2002; Vacha-Haase, 1998; Viswesvaran \& Ones, 2000), as illustrated below. To correct for unreliability, the resulting meta-analytic estimate was then adapted to the presenteeism time period used in each primary study, based on the Spearman-Brown formula. When presenteeism or other variables had been measured continuously but then dichotomized, we corrected for the resulting attenuation (Hunter \& Schmidt, 1990; 2004, p. 112). Finally, when a primary study contained information about the reliability of the correlates of presenteeism, we corrected for measurement error in the independent variable, either using the artifact distribution (i.e., if only some studies reported reliabilities) or correcting each correlation individually if we had access to the reliability coefficient for every sample. For the EWCS we were often able to calculate Cronbach alphas from the raw data separately for each country. Which of the two methods used is indicated in the note of Table 1.

Five studies used all or part of the Core Job Content Questionnaire by Karasek and colleagues (1998) to measure overall job demands, but only three of them reported reliability coefficients. Therefore, a preliminary bare-bones meta-analysis was run, yielding a meta-analytic reliability of $.71(K=3, N=2,526)$, which was then tailored to the number of items used in the remaining two studies using the Spearman-Brown formula (Hunter \& Schmidt, 2004, p. 311). Thirty eight samples (4 studies plus the EWCS survey) employed a single-item probe for job satisfaction which was corrected for measurement error using the single-item estimate from the meta-analysis by Wanous, Reichers, and Hudy (1997). For assessing the association between absenteeism and presenteeism, the absence reliability coefficient $(.53, K=95, N=25,587)$ from the meta-analysis by Johns and Al Hajj (2014) was used and tailored to the absence aggregation period of each primary study via the Spearman-Brown formula.

Finally, a series of sensitivity analyses was conducted. One set of analyses checked for differences in those studies inferring presenteeism as the correspondence of an individual's 
health with his or her working status or absenteeism level. Moreover, we re-ran the metaanalyses without the studies measuring presenteeism as mere occurrence of the behavior (whether it has happened that the individual has shown up at work when sick or not) to verify that such dichotomous measurement did not significantly affect the average effect size (Hunter \& Schmidt, 2004). A further group of analyses both excluded the EWCS sample and analyzed it separately to investigate any possible peculiarities in measurement or design characteristic of the European survey. Thus, each time a correlate had been measured within the EWCS, the 34 samples were included and excluded from the analyses, as summarized in Table 1. This applied to the following variables: health status and depression (H1); absenteeism (H2a); job insecurity, employment form, financial situation (i.e, constraints on absenteeism; H3b, c, d, respectively); physical demands and supervisory duties (i.e, role demands, H4a); work hours and time pressure (i.e, time demands, H4b); overall job demands (H4c); felt stress (H4d); work to family conflict (i.e., relational demands, H6a); job control, adjustment latitude, work significance, collegial and supervisory support, quality of leadership (i.e., job resources, H7, H8, H9a, b, d, respectively); job satisfaction (H11); demographic variables (i.e., gender, age, tenure and education); organizational sector. When a correlate was operationalized with notably different measures, as for the variable "personal financial situation," which was measured either as income or as degree of economic difficulty, meta-analyses were performed separately for each indicator. The same was done for the variables job control and collegial support, as explained below.

\section{Results}

\section{Reliability of Presenteeism}

To correct for measurement error in presenteeism, a bare-bones meta-analysis of presenteeism reliability coefficients was performed. Five studies reported a test-retest reliability coefficient for a measure of presenteeism days. Since the raw reliabilities were based on various 
query periods, we equated them to the most common time frame used in the primary studies, 12 months, using the Spearman-Brown formula (Berry, Lelchook, \& Clark, 2012; Johns \& Miraglia, 2015; Ones, Viswesvaran, \& Schmidt, 2003). Then, consistent with reliability generalization practice (e.g., Johns \& Al Hajj, 2014; Vacha-Haase, 1998; Viswesvaran \& Ones, 2000), we meta-analyzed the square roots of the converted coefficients, and the resulting meta-analytic mean was squared to obtain the overall estimate of presenteeism reliability $(.58, K=5, N=$ $10,668,95 \% \mathrm{CI}=.74, .78)$. Since one study (Taloyan et al., 2012) exhibited an incommensurate sample size ( $n=7,445$, more than the half the total sample) and a long time lag between the two waves (two years) compared to the other studies, we reran the analyses without it. The estimated reliability was $.79(K=4, N=3,223,95 \% \mathrm{CI}=.88, .91)$. Moreover, there were another six independent samples reporting alpha reliabilities for a more subjective measure of presenteeism. These studies employed a two- or three-item scale to inquire about the extent to which individuals worked when ill. We meta-analyzed them separately, following the aforementioned procedure but without correcting for time span. The estimated reliability was $.88(K=6, N=$ $2,249, \bar{r}=.94,95 \% \mathrm{CI}=.92, .95)$. In the following meta-analyses, we employed the reliability estimated on the basis of the four test-retest coefficients (i.e., .79), since it is based on days of presenteeism, the most common measure used in the primary studies. Also, it corresponds to the way the reliability of absenteeism is almost always estimated (Johns \& Al Hajj, 2014).

\section{Meta-analyses of the Correlates of Presenteeism}

Table 1 presents the results from the meta-analyses of the correlations between the independent variables and presenteeism, including sensitivity analyses.

Health. In support of H1a, general health status was negatively associated with working when ill $(\rho=-.31)$, and strengthened when we eliminated 10 samples inferring presenteeism or measuring it via a dichotomy $(\rho=-.33)$ or when we excluded the EWCS data $(\rho=-.39$; only 
EWCS $\rho=-.22$ ). The overall relationship between mental health and presenteeism was negligible $(\rho=-.05)$, but greater when 8 samples inferring presenteeism and one study with an incommensurate sample size (Hansen \& Andersen, 2008; $N=11,270)$ were omitted $(\rho=-.13$ ). Degree of depression was positively associated with going to work sick $(\rho=.20)$; again, the effect size was greater when the EWCS samples were not included $(\rho=.37$; only EWCS $\rho=$ .18). This does not support the inference that mental health and depression would be more highly related to presenteeism than general health $(\mathrm{H} 1 \mathrm{~b})$.

Absence and performance. As expected from $\mathrm{H} 2 \mathrm{a}$, the corrected population correlations between presenteeism and absenteeism was significant and positive $(\rho=.35)$, and it increased excluding the EWCS $(\rho=.50$; only EWCS $\rho=.21)$. In line with H2b, presenteeism correlated positively with productivity loss $(\rho=.28)$, which refers to the loss in productivity because of going to work ill (Schultz \& Edington, 2007). In our primary studies, productivity loss was mainly measured by asking employees how much difficulty they had experienced in completing work activities because of their ill health (e.g., the Work Limitations Questionnaire, WLQ, Lerner et al., 2001). Job performance was not significantly associated with presenteeism. Although this disconfirms the expected negative relationship $(\mathrm{H} 2 \mathrm{c})$, it does correspond to the expectation that productivity loss would be more closely connected to presenteeism than would general performance ratings.

Constraints on absenteeism. In accordance with $\mathrm{H} 3 \mathrm{a}$, stricter absence policies were associated with higher presence in spite of illness $(\rho=.39)$. As expected (H3e and H3b), ease of replacement correlated negatively with presenteeism $(\rho=-.13)$ and job insecurity related positively, particularly excluding the $\operatorname{EWCS}(\rho=.15$; only $\operatorname{EWCS} \rho=.03)$ and when a sensitivity analysis was conducted on only those studies reporting positive correlations $(\rho=.11)$. Employment form (permanent vs. temporary contract) did not exhibit a significant association 
with presenteeism. Finally, two measures indexed employees' financial situation (H3d): income and perceptions of personal financial difficulties. Income was only weakly related to presenteeism, but the estimate for personal financial difficulties was more substantial $(\rho=.10$; without the EWCS $\rho=.15$; only $\operatorname{EWCS} \rho=.09$ ).

Job demands and experienced stress. In support of H4a concerning role demands, workload $(\rho=.28)$, understaffing $(\rho=.25)$ and physical demands $(\rho=.13$; only EWCS $\rho=.18)$ exhibited the largest meta-analytic correlations with presenteeism. Also, having difficult patients or clients related positively, albeit more weakly $(\rho=.09)$. An additional meta-analysis of 4 studies indexing patient demands with the number of patients the employee had to deal with demonstrated that more patients was associated with more presenteeism $(\rho=.20)$. Marginally higher presenteeism was exhibited by supervisors $(\rho=.05)$ and this increased when the EWCS samples and two studies with extreme sample sizes (Hansen \& Andersen, 2008; Leineweber et al., 2011) were excluded ( $\rho=.17$; only EWCS $\rho=.08$ ). Finally, weak results were obtained for role conflict $(\rho=.05)$ and ambiguity $(\rho=-.02)$.

Supporting H4b, higher levels of time demands denoted increased likelihood of engaging in presenteeism, as the corrected population correlations were significant and positive for overtime work $(\rho=.15)$, long work hours $(\rho=.11$; without the $\operatorname{EWCS} \rho=.06$; only $\operatorname{EWCS} \rho=$ $.12)$, and time pressure $(\rho=.16$; without the $\operatorname{EWCS} \rho=.24$; only $\operatorname{EWCS} \rho=.14)$. The effect size for shift work was not significant. Presenteeism was positively associated with overall job demands (H4c; $\rho=.16$; without the EWCS $\rho=.19$; only EWCS $\rho=.13$ ), which, to be clear, was not calculated through the aggregation of the aforementioned subdimensions of demands (i.e., role and time demands), but rather reflects a general assessment of demands at work. Finally, working while ill related positively to the emotional exhaustion dimension of burnout $(\mathrm{H} 4 \mathrm{e} ; \rho=$ $.36)$ and felt stress $(\mathrm{H} 4 \mathrm{~d} ; \rho=.25$; only $\operatorname{EWCS} \rho=.19)$; the latter estimate was even higher $(\rho=$ 
.33) when the EWCS, one study inferring presenteeism, the studies by Leineweber et al. (2011) and Heponiemi et al. (2010) with large sample sizes $(N=11,793 ; 18,454)$ were excluded.

With regard to relational demands, corroborating H5, negative relational experiences were positively related to presenteeism in the case of discrimination $(\rho=.10)$, harassment $(\rho=$ $.16)$, and abuse $(\rho=.20)$. Additionally, both work to family and family to work conflict were positively related to presenteeism (respectively $\rho=.14, \rho=.18$ ), partially confirming H6. For work to family conflict the estimate was larger eliminating the EWCS data $(\rho=.25$; only EWCS $\rho=.14)$.

Job and personal resources. Four measures of job control were found in the primary studies: a) control over the job per se; b) adjustment latitude, c) decision authority, and d) participation (EWCS only). First, a meta-analysis was run using measures a, b, and c together. As the EWCS operationalized job control through more than one measure, this meta-analysis included only job control per se. The resulting true correlation was negative but small $(\rho=-.03$; without the EWCS $\rho=-.09$ ). Inconsistently, a sensitivity analysis focusing exclusively on the European samples showed a weak but positive population correlation $(\rho=.07)$. Then, metaanalyses were conducted separately for each measure. Control over the job per se was negatively and weakly associated with going to work when ill $(\rho=-.01)$, while the relationship was larger for adjustment latitude $(\rho=-.08)$, especially when the single-item EWCS measure was excluded $(\rho=-.19$; only EWCS $\rho=-.06)$. Associations for decision authority and participation were positive but weak $(\rho=.05 ; \rho=.03$, respectively). Thus, contrary to H7, job control was not a prominent correlate. Also, contrary to $\mathrm{H} 8$, a non-significant association with presenteeism was obtained for work significance.

A supportive workplace and positive leadership practices decreased the probability of working in an unhealthy state (H9). Two measures assessed collegial support: a direct measure 
of support from colleagues and a more general one evaluating the quality of interpersonal relationships. With regard to the first measure, the corrected correlation was negative but small $(\mathrm{H} 9 \mathrm{a} ; \rho=-.07)$ and larger when the EWCS was omitted $(\rho=-.12$; only EWCS $\rho=-.06)$.

Similarly, the corrected correlation between interpersonal relationship and presenteeism was negative but weak $(\rho=-.05)$ and increased excluding the $\operatorname{EWCS}(\rho=-.15$; only $\operatorname{EWCS} \rho=-.04)$. Negative effects were also found for the associations of presenteeism with supervisory $(\mathrm{H} 9 \mathrm{~b} ; \rho=$ -.10; without EWCS $\rho=-.13$; only EWCS $\rho=-.08$ ) and organizational support (H9c; $\rho=-.17$ ). Quality leadership (capability to encourage participation, provide feedback, plan and organize tasks) showed a true correlation of -.13 (H9d).

Among personal resources, conscientiousness and presenteeism were unrelated, disconfirming H10b. Moreover, different from H10a, optimism was negatively correlated with the tendency to show up at work ill $(\rho=-.22)$.

Job attitudes and justice. As hypothesized (H11a-c), higher levels of job satisfaction ( $\rho$ $=.12$; only EWCS $\rho=.18)$, organizational commitment $(\rho=.20)$, and work engagement $(\rho=$ .13) were associated with a greater probability of enacting presenteeism. Contrary to directional expectations (H11d), perceived organizational justice was negatively related to presenteeism $(\rho=$ $-.13)$.

Other variables. Although demographic confidence intervals did not include zero, associations were negligible. Thus, women $(\rho=.04)$, younger $(\rho=-.03)$, higher-tenured $(\rho=$ $.05)$, and more educated $(\rho=.02)$ employees were marginally more inclined toward presenteeism. Sectoral differences (public versus private) and organizational size were essentially unrelated to presenteeism.

\section{Publication Bias and Range Restriction Checks}


To test for the possible effects of publication bias, we applied the funnel plot technique (Sterne \& Egger, 2005; Sterne, Gavaghan, \& Egger, 2005) to each of the 55 general metaanalyses. This plots the effect size of each study on the X-axis and its precision (1/standard error) on the y-axis and examines the distribution for asymmetry, denoting the presence of bias. Symmetrical distributions were observed for 48 of the meta-analyses. Some asymmetry was exhibited for age, gender, productivity loss, income, work hours, job control, and adjustment latitude. The trim and fill method (Duval \& Tweedie, 2000) was then employed to impute the number of missing samples needed to correct for asymmetry and the estimated effect size if those samples were not missing. Moreover, we implemented Egger's intercept technique (Egger, Smith, Schneider, \& Minder, 1997) to test the significance of the regression intercept, which should pass through the origin in the case of a symmetric distribution. The reduction in effect size calculated through trim and fill was negligible, since the new estimates fell into the $95 \% \mathrm{CI}$ of the original meta-analysis, except for work hours and income. Additionally, the intercept test only reached significance for work hours $(\beta=2.48, p<.01)$ and job control $(\beta=3.24, p<.01)$. In sum, we found little evidence for publication bias.

It will have been noticed that in some cases the population correlations were higher when the EWCS samples were removed from consideration. To understand whether this was due to some peculiarities of the EWCS database, we first checked for range restriction in the measure of presenteeism, contrasting the standard deviations of the 34 European samples and the reference population standard deviation, calculated on all the primary studies (Hunter \& Schmidt, 2004). No evidence of restriction was found. Additionally, for those variables reflecting larger differences in the estimated correlations between the overall meta-analysis and the sensitivity analysis that excluded the EWCS (depression, absenteeism, time pressure, adjustment latitude, felt stress, relationship with colleagues, work to family conflict, organizational sector), we tested 
for possible asymmetric distributions in the European samples using the funnel plot technique. Again, the results did not show any bias in the EWCS data.

\section{The Meta-analytic Model}

To test the empirical model, meta-analytic structural equation modeling (SEM, Viswesvaran \& Ones, 1995) was implemented. To obtain a parsimonious model, we favored global variables, as in the case of overall job demands and job control. Moreover, we retained only those variables which had been reported in numerous primary studies, so that the metaanalytic estimates were based on sufficient $K$ and cumulative sample size. The resulting model included job insecurity and personal financial difficulties among constraints on absenteeism, job demands, job control, and several resources (collegial support, supervisor support, optimism). Both the Luchman and González-Morales (2013) meta-analysis and our own fit analyses suggested separating rather than combining the two support measures. The mediating variables were general health, denoting the health impairment path, and job satisfaction, representing the attitudinal/motivational path. Although the JD-R model would also accept commitment and engagement as mediators, we only had sufficient $K$ to employ satisfaction. Finally, since gender is often relevant to absenteeism (Côté \& Haccoun, 1991; Patton \& Johns, 2011, 2102), we controlled for it.

Meta-analytic SEM requires a complete matrix of effects (Table 2). We used the estimates already reported in Table 1 for the relationships with presenteeism and, where possible, we retrieved the correlations from past meta-analyses for the other non-focal relationships (e.g., support-job control, job insecurity-job satisfaction). For those relationships never synthetized previously we conducted our own meta-analyses using correlations from the 109 presenteeism samples. Original meta-analyses were performed for all the relationships pertaining absenteeism to have a homogeneous set of articles identical to those used for presenteeism (e.g., including the 
EWCS). In some cases, the $K$ for our meta-analyses was larger than those reported in the literature. However, our estimates were very close to previous research: for example, our estimate of the association between job satisfaction and absenteeism $(\rho=-.19)$ was squarely in the middle of the estimates provided in several previous meta-analyses (Farrell \& Stamm, 1988; Hackett, 1989; Scott \& Taylor, 1985). The source of each correlation is specified in the note for Table 2.

To estimate the SEMs with Mplus 7.1 (Muthén \& Muthén, 2012) we used manifest indicators without correction for measurement error, as these corrections were accomplished with meta-analysis, and we employed the harmonic mean sample size $(N=40,006)$ from the correlation matrix (Viswesvaran \& Ones, 1995). Absenteeism and presenteeism were allowed to covary freely, since our meta-analysis showed a robust association between the two variables.

The model fit the data well, $X^{2}(3)=644.02, p<.001, \mathrm{CFI}=.99, \mathrm{TLI}=.96, \mathrm{RMSEA}=$ .06, SRMR $=.01$ (Brown \& Cudeck, 1992; Hu \& Bentler, 1998). Figure 2 presents the parameter estimates while Table 3 reports the standardized coefficients for the direct links of the exogenous variables with absenteeism and presenteeism. As expected, job insecurity, personal financial difficulties and job demands related negatively to job satisfaction while control over the job, both forms of support, and optimism related positively. Higher levels of insecurity, financial difficulties, and demands were associated with a decrement in health whereas job control, the two facets of support and optimism signaled good health. In turn, job satisfaction related negatively to absenteeism and positively to presenteeism while poor health conditions were strongly associated with both attendance behaviors. Thus, the indirect effects on presenteeism and absenteeism via job satisfaction and health were all significant, as verified by a Sobel (1982) test (Table 3). Women reported more absenteeism and marginally more presenteeism. The model explained more variance in presenteeism (32\%) than absenteeism (14\%), as anticipated in the 
literature (Johns, 2010). The variance explained in the mediators was $44 \%$ for job satisfaction and $20 \%$ for health.

At the suggestion of a reviewer, we replicated the meta-analytic SEM with a simple structural equation model using only the EWCS data, estimated in Mplus 7.1 (Muthén \& Muthén, 2012). This has the advantage of assessing each construct with a single standard measure, thus providing a covariance matrix. Given several single-item measures, variables were entered as observed indicators. The model fit the data well, $X^{2}(3)=669.40, p<.001, \mathrm{CFI}=.96$, $\mathrm{TLI}=.92, \mathrm{RMSEA}=.09, \mathrm{SRMR}=.01$ (Brown \& Cudeck, 1992; Hu \& Bentler, 1998), and overall, replicated the findings of meta-analytic SEM, as all effects were in the same direction as those resulting from the meta-analytic model. Hence, job insecurity and financial difficulties related negatively to job satisfaction while control, both forms of support, and optimism related positively. Moreover, job insecurity, financial difficulties, and job demands were negatively associated with the health status whereas support and optimism related positively. In turn, job satisfaction related negatively to absenteeism and positively to presenteeism while poor health conditions were associated with both attendance behaviors. Different from the meta-analytic model, the links between job demands and job satisfaction as well as between job control and health did not reach significance $(p>.05)$. Thus, the indirect effects on presenteeism and absenteeism via job satisfaction and health were all significant, as verified by a Sobel (1982) test, except for those concerning job demands and control. The explained variance was slightly higher for presenteeism (10\%) than absenteeism (7\%). The variance explained in the mediators was $26 \%$ for job satisfaction and $17 \%$ for health. Graphical and tabular results for these analyses are available from the first author.

\section{Discussion}


Two purposes of this research were to provide a quantitative synthesis of the correlates of presenteeism and to propose and verify a partial model of these correlates which integrated a parsimonious set of contextual and personal variables in relationship to presenteeism and absenteeism. An additional purpose was to contrast the etiology of presenteeism versus absenteeism.

Starting with the association of presenteeism with health, absenteeism, and performance, overall health figured as a prominent correlate. This expected result establishes the basis for the validity of the construct, since it is defined as going to work when ill. However, we could not verify the assumption that mental health and depression would be more closely connected to presenteeism than overall health, something that might be inferred from the occupational medicine literature on productivity loss. It is possible that this result is a function of base rates, in that more specific illnesses are rarer events than aggregates of such illnesses. It is also plausible that, as employees see mental illness or depression as relatively less legitimate reasons to be absent (Johns \& Xie, 1998), they would not view them as causes of presenteeism. In other words, individuals suffering from mental illness might not perceive themselves as ill and might not include mental ailments among sickness indicators, as they do for more recognizable and visible physical complaints. Thus, they might not consider attending work while mentally unwell as presenteeism, explaining the failure to prove the predicted stronger effect of mental health and depression on working while ill.

Regarding the association between presenteeism and absenteeism, as expected, people in poorer health exhibited more of both behaviors. However, more research is desirable to explore the causal link between the two variables, to understand how presenteeism may further harm health (Bergström et al., 2009; Gustafsson \& Marklund, 2011; Kivimäki et al., 2005), increasing subsequent absenteeism. Unfortunately, most research reviewed here was cross-sectional. 
Despite the large amount of research on productivity loss associated with various medical conditions, only four studies simultaneously investigated productivity loss and the act of presenteeism, specifically measured. This can be explained by the fact that presenteeism has been conceptualized in the occupational medicine literature as a reduction in productivity due to health (Schultz \& Edington, 2007) without directly measuring the act of going to work ill. However, the two variables are positively related, confirming that individual productivity can suffer from working while ill, whatever the specifics of the illness. Presenteeism was unrelated to performance ratings in four primary studies. Additional research is warranted to understand the effects of working when ill on the performance dynamic, clarifying how supervisors evaluate presenteeism, whether they are aware of the phenomenon, or whether they underestimate or encourage it (Pauly, Nicholson, Polsky, Berger, \& Sharda, 2008). Indeed, some managers may think that illness at work does little damage to performance (Pauly et al., 2008) and perceive presenteeism as an expression of commitment to the organization. Showing up while sick can be seen as an employee's effort to contribute, as a form of organizational citizenship behavior (Johns, 2010). As a consequence, supervisors might reward it, assessing performance more positively, and this could nullify any negative relationship between presenteeism and rated job performance.

Besides health, which are the most salient correlates and causes of going to work when ill? The answer seems to lie in any source of high obligation to work, whether work- or personrelated. To organize these work and personal correlates, we proposed and tested a mediated dualpath model, which relies on the DCS model (Johnson \& Hall, 1988; Johnson et al., 1989; Karasek, 1979) and the JD-R framework (Bakker et al., 2014). The results of the meta-analytic structural equation model help to explain the hypothesized direct links between working while ill and its antecedents. More important, they shed light on some paradoxes concerning the behavior 
and its etiology: Why should people already taxed by high job demands and job stressors spend more time at work while suffering medically? Or why should individuals continue to work when sick when they have high control over their activities, can modify the pace of their work, and can rely on a supportive and sympathetic work environment? The dual-path model speaks to these contradictions and resolves some of the inconsistent findings reported in the literature, such as for job control and social support, as further discussed below. Indeed, our model demonstrated how work and personal characteristics relate differently to presenteeism depending on whether they follow health impairment or attitudinal/motivational paths. Thus, the two mediating mechanisms of the model are individual health (i.e., health impairment path) and motivation, stemming from high job satisfaction (i.e., attitudinal/motivational path). We have already discussed the negative link between individual health and presenteeism. With regard to the attitudinal/motivational mechanism, we found that motivation to attend is influenced by job attitudes. High satisfaction with the job, elevated work engagement, and a strong sense of affective commitment to the organization may motivate people to spend greater energy and time at work, to "go to the extra-mile," inducing them not only to work more intensively (Christian, Garza, \& Slaughter, 2011; Macey \& Schneider, 2008; Pfeffer, 1998) but also trigging pressure to work in an unhealthy condition. The positive association between attitudes and presenteeism is corroborated by our qualitative review of several studies which asked respondents to explain their presenteeism. The most frequent answers included interest and pleasure derived from work activities (Biron, Brun, Ivers, \& Cooper, 2006; Krohne \& Magnussen, 2011) and a sense of commitment toward the organization (Falco, 2013; Taylor, Cunningham, Newsome, \& Scholarios, 2010) or to the job per se (Caverley et al., 2007; McKevitt et al., 1997; Quazi, 2012). Among the sources of obligation to work, presenteeism was positively related to the severity of organizational policies used to monitor or reduce absenteeism, such as strict trigger 
points for disciplinary actions, a low level of remunerated sick leave, or few absence days available without medical certification. The other constraints on absence (i.e., difficulty of replacement, job insecurity, and personal financial difficulties) exhibited small but positive associations with presenteeism. In general, absence constraints emphasize the possible adverse consequences of absenteeism and, thus, its risky nature, inducing employees to show up ill or to return to work when not totally recovered. This provides some support for the substitution hypothesis (Caverley et al., 2007), since constraints can effectively reduce absence (Farrell \& Stamm, 1988; Johns, 2008), but at the cost of increased presenteeism.

Job demands represent a second crucial compulsion to attend. Heavy workload, understaffing, overtime, and time pressure are all factors requiring presence to deal with a high volume of work and meet tight timelines. According to conservation of resources theory (Hobfoll, 2001), an individual facing high job demands, felt stress, and exhaustion may be induced to work excessively long hours and when ill to compensate any possible decrements in productivity or resources (Demerouti et al., 2009; Freudenberger \& Richelson, 1980). Furthermore, job demands may harm health and well-being and thus indirectly prompt the tendency to work when sick, operating through the health impairment process. However, following the attitudinal/motivational path of our model, job demands are also indirectly and negatively related to presenteeism, due to their negative connection with job satisfaction that, in turn, is positively associated with continuing to work when ill. The same reasoning and results apply to the indirect associations between constraints on absenteeism and presenteeism. Absenteeism constraints are positively associated to the phenomenon through the health impairment mechanism, but they negatively relate to it via the attitudinal/motivational process. When it comes to presenteeism, job resources seem to directly countervail demands only weakly/partially. Work significance was unrelated to going to work ill, and the direct association 
with job control was weak. This said, the SEM model suggests the indirect merits of job control, which was indirectly and negatively related to working while sick, since it enhance employee health and wellbeing. More interesting, the indirect links of the dual-path model reconcile the mixed evidence in the literature, which reports positive, negative, and non-significant associations between control and presenteeism (e.g., Aronsson \& Gustafsson, 2005; Deery et al., 2012; Gustafsson \& Marklund, 2011). It is true, in fact, that job control negatively relates to working in an unhealthy condition both directly and indirectly, but the SEM model also suggests that higher levels of control may indirectly trigger presenteeism through the attitudinal/motivational path. In fact, individuals who can rely on higher levels of control over the job are more satisfied, suggesting a positive link with presenteeism.

A supportive work environment was directly and negatively associated with going to work when ill, even if some caution is needed in interpreting this result, due to the weak population correlation for collegial support. In general, helpful colleagues, a supportive and trusting relationship with the supervisor, and a supportive organization can enhance selfdisclosure of illness (Munir et al., 2005), reduce the perception of absence as an unjustified behavior, and facilitate the possibility of being replaced in case of sickness, encouraging employees to remain at home when ill. Moreover, a supportive work context is a buffer against strain, obstacles, and work-related health problems (Biron \& Bamberger, 2012; Väänänen et al., 2003), lowering presenteeism risk, as proved by the indirect and negative link of supervisory and collegial support with working when sick through the health impairment path. Again, the dualpath model facilitates the reading of the contradictory findings on social support existing in the literature (e.g., Baker-McClearn, Greasley, Dale, \& Griffith, 2010; Biron et al., 2006; Caverly et al., 2007; Hansen \& Andersen, 2008). Individuals who benefit from greater workplace support 
are both more satisfied and healthier; this explains why support may exhibit both positive and negative relations with presenteeism.

With regard to personal resources, the direct relationship between optimism and presenteeism was negative, inconsistently with what was hypothesized. It is plausible that feeling active, calm, interested, and in a good mood serves as a buffer mechanism to reduce experienced stress and enhance health and well-being (Xanthopoulou et al., 2009), so decreasing presenteeism. Once again, this explanation is confirmed by the health impairment path of our model: optimism supports health which, in turn, diminishes the probability of working in presence of medical complaints. Nevertheless, as for job resources, a positive indirect link with presenteeism is suggested via the motivational/attitudinal path, as optimism results in increased job satisfaction, which triggers presenteeism.

With regard to negative relational experiences, as expected, being exposed to harassment, abuse, and discrimination related positively to presenteeism, as they are analogous to hindrance job demands, exacerbating stress and harming health (Bowling \& Beehr, 2006; O’Leary-Kelly et al., 2009; Willness et al., 2007). Finally, both work to family conflict and family to work conflict exhibited positive relationships with presenteeism. The former is symptomatic of a highly demanding work context, which both causes familial conflict and requires attendance. The latter positive correlation might reflect the "home becoming work" effect (Hochschild, 1997), in that in some cases home life can be so taxing that people might prefer to attend a motivating and stimulating job, even when in not perfect health.

In sum, a significant contribution of this study is to clearly demonstrate that presenteeism is associated with work features and personal characteristics and not fully dictated by medical condition, in contrast to the predominant perspective of occupational medicine and epidemiology (Goetzel et al., 2009; Kessler et al., 2003; Schultz \& Edington, 2007). Furthermore, the key 
contribution of the study is to systematize those work and personal variables in a broader dualpath model, which enables greater understanding of some enigmas in presenteeism causation.

An additional purpose of the study was to contrast the explanatory value of the contextual and personal variables with regard to presenteeism versus absenteeism. The inclusion of absenteeism in the structural model allowed us also to compare the etiology of the two attendance behaviors. Notably, the majority of the work and personal characteristics revealed relationships in the same direction for both behaviors. Specifically, impaired health and job demands were positively and directly related to both behaviors while job control and optimism related negatively. However, it is important to understand that these variables could be positively or negatively associated with employee's presence or absence depending on different circumstances and mechanisms, as highlighted by the indirect effects of the models. Indeed, job demands can stimulate both behaviors due to its negative effect on health, but, when the mediating role of job satisfaction is taken into account, demands are associated with lower presenteeism but higher absenteeism. Job control and optimism are negatively related to both absence and presence via health; however, they are associated with higher presenteeism but lower absenteeism via job satisfaction. The remaining direct links of the structural equation model provide some support for the substitution hypothesis (Caverley et al., 2007), indicating that in some instances engaging in one behavior excludes the other. First, job insecurity had a negative and direct relationship with absence, as already observed in the literature (Caverley et al., 2007; Kivimäki, Vahtera, Pentti, \& Ferrie, 2000), but a positive one with presenteeism. Second, in line with Hackett's (1989) meta-analysis and the withdrawal model of absenteeism (Johns, 1997), job satisfaction was associated with lower absence, but strongly positively associated with presence. Third, collegial support was a deterrent for presenteeism, increasing absenteeism. All in all, the direct links from the contextual and personal variables to 
presenteeism seem to uncover a third pathway, along with the health impairment and attitudinal/motivational processes but not explicitly specified in the model. The third path may reflect the employee's felt obligation to attend. That is, high levels of job insecurity, personal financial difficulties and job demands likely trigger attendance pressure, increasing obligation to work when ill to avoid any job dismissal or deal with the fear of it under uncertain conditions as well as to handle heavy workload and strict time schedules. Similarly, the lack of control over one's activities, tasks and time and insufficient supervisory or collegial support, which for instance may preclude employees' replacement, are able to exacerbate obligation to attend, forcing presenteeism. Future research may better explore this third mediating path, directly measuring the employees' perception of being obligated to show up at work even if ill.

Although many variables were related to both attendance behaviors, the magnitude of the links was systematically greater for presenteeism than absenteeism. Thus, the models explained more variance in presenteeism. Although absenteeism is a discrete, observable, and often documented event, presenteeism involves subjective assessment of one's medical condition, one's capabilities to deal with job demands despite illness, and the available job and personal resources which can facilitate performing the job. Therefore, presenteeism is more in the eye of the beholder and more predictable with self-reported work and personal characteristics.

A resulting practical implication of greater predictability is that presenteeism may be more modifiable and controllable than absenteeism, more sensitive to human resources policies and interventions. In light of the high cost of presenteeism for organizational productivity (Cooper \& Dewe, 2008; Hemp, 2004), workplace wellness and health programs may be desirable to reduce felt stress and work-related illness, primary causes of going to work sick. Moreover, although increasing job resources can be helpful in light of their indirect link with presenteeism through their positive impact on satisfaction and health, our results suggest that controlling job 
demands represents a prime line of defense against the behavior due to their direct and indirect effects. Thus, organizations may benefit from well-designed jobs that optimize the level of demands to which employees are exposed, reducing excessive workload, time pressure, and overtime work. Also, organizations may want to carefully audit attendance policies for features which could decrease absence at the cost of elevated presenteeism.

Our study sheds some clarity on another important issue: should we view presenteeism as a positive or negative phenomenon? The dual path model recognizes that it can be generated both by decay in health and by experienced job satisfaction. The latter case reflects a more positive, motivating process, which pushes the employee to put more time and energy into the job, in line with the idea that presenteeism can reflect organizational citizenship (Johns, 2010). However, presenteeism can lead to negative consequences, as it can: cause serious health problems in the long term (Bergström et al., 2009; Hansen \& Andersen, 2008; Kivimäki et al., 2005); impair coworkers' health through contagion (Ramsey, 2006); harm productivity, affecting work quantity and quality (Hemp, 2004); damage work-life balance and the general quality of life. In this light, more research is needed to understand when going to work while ill can represent a "sustainable" choice, as in the case of a gradual recovery from long-term sickness, a self-affirming choice in the face of chronic illness, or being an example of citizenship behavior.

\section{Limitations and Future Directions}

We recognize that we have a limited estimate of the reliability of presenteeism, based on only four test-retest coefficients. However, our estimate of .79 is consistent with the population reliability for self-reported absenteeism (.79; Johns \& Miraglia, 2015). Moreover, an intrinsic limitation of meta-analysis is that not all existing studies might have been included, as we could have missed some samples despite our computerized and manual searches. Also, the primary studies on which the meta-analyses are based used self-reported data, except for those which 
inferred presenteeism from an individual's health and his or her absenteeism rate or working status. Furthermore, all but five studies relied on cross-sectional data. The use of cross-sectional self-reports may foster common method variance, although presenteeism is a construct for which it is difficult to find alternative sources. We acknowledge that structural models based on correlation matrices may generate incorrect standard errors, often overestimating them (Cudeck, 1989). However, this leads to more conservative parameter tests and has been used in much previous literature. Also, although our hypotheses draw upon previous literature and established theoretical models, such as the DCS (Karasek \& Theorell, 1990) or the JD-R models (Bakker, Demerouti, \& Sanz-Vergel, 2014), meta-analyses of correlations do not provide clear casual relationships among variables or account for reciprocal causation. Future longitudinal studies are needed to effectively test the possibility of reciprocal associations between our designated antecedents and working while ill. For example, presenteeism might exacerbate strain and exhaustion, as it diminishes the capacity to fully recover, causing a negative loop.

A particularly fruitful path for future research would be the application of experience sampling methods as well as qualitative research to better probe the dual path dynamics (i.e. the tradeoff between health and motivation) identified in our quantitative models. Experience sampling would permit a real-time, within-person examination of discrete decisions to attend when ill or to be absent, including the identification of various profiles of presentees. Qualitative research would better elucidate the psychology behind such decisions, particularly with regard to the self-disclosure of illness in the workplace and the social factors impinging on absencepresence decisions. 


\section{References}

References marked with an asterisk $(*)$ indicate studies included in the meta-analyses.

*Ablah, E., Konda, K., Tinius, A., Long, R., Vermie, G., \& Burbach, C. (2008). Influenza vaccine coverage and presenteeism in Sedgwick County, Kansas. American Journal of Infection Control, 36, 588-91.

Addae, H. M., Johns, G., \& Boies, K. (2013). The legitimacy of absenteeism from work: A nine nation exploratory study. Cross Cultural Management, 20, 402-428.

*Agudelo-Suárez, A. A., Benavides, F. G., Felt, E., Ronda-Pérez, E., Vives-Cases, C., \& García, A. M. (2010). Sickness presenteeism in Spanish-born and immigrant workers in Spain. BMC Public Health, 10, 791.

*Aronsson, G., \& Gustafsson, K. (2005). Sickness Presenteeism: Prevalence, AttendancePressure Factors, and an Outline of a Model for Research. Journal of Occupational and Environmental Medicine, 47, 958-966.

*Aronsson, G., Gustafsson, K., \& Dallner, M. (2000). Sick but yet at work. An empirical study of sickness presenteeism. Journal of Epidemiology and Community Health, 54, 502-509.

*Aronsson, G., Gustafsson, K., \& Mellner, C. (2011). Sickness presence, sickness absence, and self-reported health and symptoms. International Journal of Workplace Health Management, $4,228-243$.

Baker-McClearn, D., Greasley, K., Dale, J., \& Griffith, F. (2010). Absence management and presenteeism: The pressures on employees to attend work and the impact of attendance on performance. Human Resource Management Journal, 20, 311-328.

Bakker, A. B., \& Demerouti, E. (2006). The Job Demands-Resources model: State of the art. Journal of Managerial Psychology, 22, 309-328. 
Bakker, A. B., Demerouti, E., \& Euwema, M. C. (2005). Job resources buffer the impact of job demands on burnout. Journal of Occupational Health Psychology, 10, 170-80.

Bakker, A. B., Demerouti, E., \& Sanz-Vergel, A. A. (2014). Burnout and work engagement: The JD-R approach. Annual Review of Organizational Psychology and Organizational Behavior, $1,389-411$.

Barrick. M. R., \& Mount, M. K. (1991). The big five personality dimensions and job performance: A meta-analysis. Personnel Psychology, 44, 1-26.

Bergström, G., Bodin, L., Hagberg, J., Lindh, T., Aronsson, G., \& Josephson, M. (2009). Does sickness presenteeism have an impact on future general health? International Archives of Occupational and Environmental Health, 82, 1179-1190.

Berry, C. M., Lelchook, A. M., \& Clark, M. A. (2012). A meta-analysis of the interrelationships between employee lateness, absenteeism, and turnover: Implications for models of withdrawal behavior. Journal of Organizational Behavior, 33, 678-699.

Biron, C., Brun, J., Ivers, H., \& Cooper, C. L. (2006). At work but ill: Psychological work environment and well-being determinants of presenteeism propensity. Journal of Public Mental Health, 5, 26-37.

Biron, M., \& Bamberger, P. (2012). Aversive workplace conditions and absenteeism: Taking referent group norms and supervisor support into account. Journal of Applied Psychology, 97, 901-912,

*Bracewell, L. M., Campbell, D. I., Faure, P. R., Giblin, E. R., Morris, T. A., Satterthwaite, L. B., ... Holmes, J. D. (2010). Sickness presenteeism in a New Zealand hospital. The New Zealand Medical Journal, 123, 30-41.

Borenstein, M., Hedges, L. V., Higgins, J. P. T., \& Rothstein, H. R. (2009). Introduction to metaanalysis. Chichester, UK: Wiley. 
Bowling, N. A., \& Beehr, T. A. (2006). Workplace harassment from the victim's perspective: A theoretical model and meta-analysis. Journal of Applied Psychology, 91, 998-1012.

Bowling, N. A., \& Kirkendall, C. (2012). Workload: A review of causes, consequences, and potential interventions. In J. Houdmont, S. Leka, \& R. R. Sinclair (Eds.), Contemporary occupational health psychology: Global perspectives on research and practice (Vol. 2, pp. 221-238). Chichester, UK: Wiley-Blackwell.

Brown, M. W., \& Cudeck, R. C. (1992). Alternative way of assessing model fit. Sociological Methods \& Research, 21, 230-258.

Brush, D. H., Moch, M. K., \& Pooyan, A. (1987). Individual demographic differences and job satisfaction. Journal of Occupational Behaviour, 8, 139-156.

Caruso, C. C., Hitchcock, E. M., Dick, R. B., Russo, J. M., \& Schmit, J. M. (2004). Overtime and extended work shifts: Recent findings on illnesses, injuries, and health behaviors. DHHS (NIOSH) Publication No. 2004-143. Cincinnati, OH: National Institute for Occupational Safety and Health.

*Caverley, N., Cunningham, J. B., \& MacGregor, J. N. (2007). Sickness presenteeism, sickness absenteeism, service organization. Journal of Management Studies, 44, 304-319.

Chiaburu, D. S., \& Harrison, D. A. (2008). Do peers make the place? Conceptual synthesis and meta-analysis of coworker effects on perceptions, attitudes, OCBs, and performance. Journal of Applied Psychology, 92, 1082-1103.

Cheng, G. H.-L., \& Chan, D. K.-S. (2008). Who suffers more from job insecurity? A metaanalytic review. Applied Psychology: An International Review, 57, 272-303.

Christian, M. S., Garza, A. S., \& Slaughter, J. E. (2011). Work engagement: A quantitative review and test of its relations with task and contextual performance. Personnel Psychology, 64, 89-136. 
Christie, V. M., \& Ingstad, B. (1996). Reluctant to be perceived as ill--the case of the physician. In O. Larsen (Ed.), The shaping of a profession. Norwegian physicians past and present (pp. 491-499). Canton, MA: Science History Publications.

*Cicei, C. C., Mohorea, L., \& Teodoru, A. A. (2013). Investigating two predictors of sickness presenteeism on a romanian sample. The case of performance-based self-esteem and overcommitment. Procedia - Social and Behavioral Sciences, 78, 325-329.

*Claes, R. (2011). Employee correlates of sickness presence: A study across four European countries. Work \& Stress, 25, 224-242.

Clough, S. (2011). Gender and the hygiene hypothesis. Social Science \& Medicine, 72, 486-493.

*Cocker, F., Martin, A., Scott, J., Venn, A., Otahal, P., \& Sanderson, K. (2011). Factors associated with presenteeism among employed Australian adults reporting lifetime major depression with 12-month symptoms. Journal of Affective Disorders, 135, 231-240.

*Cocker, F., Martin, A., Scott, J., Venn, A., \& Sanderson, K. (2013). Psychological distress, related work attendance, and productivity loss in small-to-medium enterprise owner/managers. International Journal of Environmental Research and Public Health, 10, $5062-5082$.

Collins, J. J., Baase, C. M., Sharda, C. E., Ozminkowski, R. J., Nicholson, S., Bilotti, G. M., ... Berger, M. L. (2005). The assessment of chronic health conditions on work performance, absence, and total economic impact for employers. Journal of Occupational and Environmental Medicine, 47, 547-557.

*Consiglio, C., \& Alessandri, G. (2014, April). Presenteeism as a catalyst of burnout consequences: Effect on health and performance. Paper presented at the $11^{\text {th }}$ Conference of the European Academy of Occupational Health Psychology, London, UK. 
Cooper, C., \& Dewe, P. (2008). Well-being: Absenteeism, presenteeism, costs and challenges. Occupational Medicine, 58, 522-524.

Corrigan, P. W. (Ed.). (2005). On the stigma of mental illness: Practical strategies for research and social change. Washington, DC: American Psychological Association.

Côté, D., \& Haccoun, R. R. (1991). L’absentéisme des femmes et des homes: Une méta -analyse. Canadian Journal of Administrative Sciences, 8, 130-139.

Crawford, E. R., LePine, J. A., \& Rich, B. L. (2010). Linking job demands and resources to employee engagement and burnout: A theoretical extension and meta-analytic test. Journal of Applied Psychology, 95, 834-848.

Crout, L. A., Chang, E., \& Cioffi, J. (2005). Why do registered nurses work when ill? The Journal of Nursing Administration, 35, 23-28.

Cudeck, R. (1989). Analysis of correlation matrices using covariance structure models. Psychological Bulletin, 105, 317-327.

Dalal, R. S., Baysinger, M., Brummel, B. J., \& LeBreton, J. M. (2012). The relative importance of employee engagement, other job attitudes, and trait affect as predictors of job performance. Journal of Applied Social Psychology, 42, E295-E325.

Darr, W., \& Johns, G. (2008). Work strain, health, and absenteeism: A meta-analysis. Journal of Occupational Health Psychology, 13, 293-318.

*d'Errico, A., Viotti, S., \& Baratti, A. (2013). Low back bain and associated presenteeism among hospital nursing staff. Journal of Occupational Health, 55, 276-283.

Dello Russo, S., Miraglia, M., Borgogni, L., \& Johns, G. (2013). How time and perceptions of social context shape employee absenteeism trajectories. Journal of Vocational Behavior, 83, 209-217. 
*De Perio, M. A., Wiegand, D. M., \& Brueck, S. E. (2014). Influenza-like illness and presenteeism among school employees. American Journal of Infection Control, 42, 450-452.

*Deery, S., Iverson, R. D., \& Walsh, J. (2012, August). Why do employees work when ill? A study of the antecedents and outcomes of presenteeism. Paper presented at the Academy of Management annual meeting, Boston, MA.

*Deery, S., Walsh, J., Zatzick, C. D., \& Iverson, R. D. (2014). A moderated mediation analysis of job demands, presenteeism and absenteeism. Journal of Occupational and Organizational Psychology, 87, 352-369.

Demerouti, E., Bakker, A. B., \& Bulters, A. J. (2004). The loss spiral of work pressure, workhome interference and exhaustion: Reciprocal relations in a three-wave study. Journal of Vocational Behavior, 64, 131-149.

*Demerouti, E., Le Blanc, P. M., Bakker, A. B., Schaufeli, W. B., \& Hox, J. (2009). Present but sick: A three-wave study on job demands, pres enteeism and burnout. Career Development International, 14, 50-68.

Diestel, S., Wegge, J., \& Schmidt, K-H. (2014). The impact of social context on the relationship between individual job satisfaction and absenteeism: The roles of different foci of job satisfaction and work-unit absenteeism. Academy of Mangement Journal, 57, 353-382.

Digman, J. M. (1990). Personality structure: Emergence of the five-factor model. Annual Review of Psychology, 41, 417-440.

Duval, S. J., \& Tweedie, R. L. (2000). Trim and fill: A simple funnel plot-based method of testing and adjusting for publication bias in meta-analysis. Biometrics, 56, 455-463.

Egger, M., Smith, G. D., Schneider, M., \& Minder, C. (1997). Bias in meta-analysis detected by a simple, graphical test. British Medical Journal, 315, 629-634. 
*Elstad, J. I., \& Vabø, M. (2008). Job stress, sickness absence and sickness presenteeism in Nordic elderly care. Scandinavian Journal of Public Health, 36, 467-74.

*European Foundation for the Improvement of Living and Working Conditions, European Working Conditions Survey, 2010 [Computer file]. Colchester, Essex: UK Data Archive [Distributor], February 2012. SN: 6971, http://dx.doi.org/10.5255/UKDA-SN-6971-1

*Falco, A., Girardi, D., \& Parmiani, G. (2013). Presenteismo e salute dei lavoratori: Effetti di mediazione sullo strain psico-fisico in un'indagine longitudinale. Giornale Italiano di Medicina del Lavoro ed Ergonomia, 35, 138-150.

Faragher, E. B., Cass, M., \& Cooper, C. L. (2005). The relationship between job satisfaction and health: A meta-analysis. Occupational and Environmental Medicine, 62, 105-112.

Farrell, D., \& Stamm, C. L. (1988). Meta-analysis of the correlates of employee absence. Human Relations, 41, 211-227.

Fidelman, C. (2009, October 15). Flu symptoms don't keep Quebecers at home. The Gazette. Retrived from http://www.montrealgazette.com

Ford, M. T., \& Huang, J. (2014). The health consequences of organizational injustice: Why do they exist and what can be done? In S. Leka, \& R.R. Sinclair (Eds.), Contemporary occupational health psychology: Global perspectives on research and practice (Vol. 3, pp. 35-50). Chichester, UK: Wiley-Blackwell.

Freudenberger, H. J., \& Richelson, G. (1980). Burnout: The cost of achievement. Garden City, NY: Doubleday.

Frone, M. R., Yardley, J. K., \& Markel, K. S. (1997). Developing and testing an integrative model ofthe work-family interface. Journal of Vocational Behavior, 50, 145-167

Ganster, D. C., \& Rosen, C. C. (2013). Work stress and employee health: A multidisciplinary review. Journal of Management, 39, 1085-1122. 
*Gerich, J., (2014). Sickness presence, sick leave and adjustment latitude. International Journal of Occupational Medicine and Environmental Health, 27, 736-746.

Geurts, S. A. E, Kompier, M. A. J., Roxburgh, S., \& Houtman, I. L. D. (2003). Does work-home interference mediate the relationship between workload and well-being? Journal of Vocational Behavior, 63, 532-559.

Glazer, S., Kozusznik, M. W., Meyers, J. H., \& Ganai, O. (2014). Meaningfulness as a resource to mitigate work stress. In S. Leka, \& R. R. Sinclair (Eds.), Contemporary occupational health psychology: Global perspectives on research and practice (Vol. 3, pp. 114-130). Chichester, UK: Wiley-Blackwell.

Goetzel, R. Z., Carls, G. S., Wang, S., Kelly, E., Mauceri, E., Columbus, D., Cavuoti, A. (2009). The relationship between modifiable health risk factors and medical expenditures, absenteeism, short-term disability, and presenteeism among employees at Novartis. Journal of Occupational and Environmental Medicine, 51, 487-499.

Goldberg, L. R. (1990). An alternative "description of personality": The big five factor structure. Journal of Personality and Social Psychology, 59, 1216-1229.

*Gosselin, E., Lemyre, L., \& Corneil, W. (2013). Presenteeism and absenteeism: Differentiated understanding of related phenomena. Journal of Occupational Health Psychology, 18, 75-86.

Grant, A. M. (2008). The significance of task significance: Job performance effects, relational mechanisms, and boundary conditions. Journal of Applied Psychology, 93, 108-124.

*Gustafsson, K., \& Marklund, S. (2011). Consequences of sickness presence and sickness absence on health and work ability: A Swedish prospective cohort study. International Journal of Occupational Medicine and Environmental Health, 24, 153-65.

Hackett, R. D. (1989). Work attitudes and employee absenteeism: A synthesis of the literature. Journal of Occupational Psychology, 62, 235-248. 
*Hansen, C. D., \& Andersen, J. H. (2008). Going ill to work--what personal circumstances, attitudes and work-related factors are associated with sickness presenteeism? Social Science \& Medicine, 67, 956-64.

Hemp, P. (2004, October). Presenteeism: At work-but out of it. Harvard Business Review, 4958.

Henson, R. K. , \& Thompson, B. (2002). Characterizing measurement error in scores across studies: Some recommendations for conducting "reliability generalization" (RG) studies. Measurement and Evaluation in Counseling and Development, 35, 113-127.

*Heponiemi, T., Elovainio, M., Pentti, J., Virtanen, M., Westerlund, H., Virtanen, P., ... Vahtera, J. (2010). Association of contractual and subjective job insecurity with sickness presenteeism among public sector employees. Journal of Occupational and Environmental Medicine, 52, $830-835$.

Hochschild, A. (1997). The time bind. When work becomes home and home becomes work. New York, NY: Metropolitan Books.

Hinshaw, S. P. (2007). The mark of shame: Stigma of mental illness and an agenda for change. New York, NY: Oxford University Press.

Hobfoll, S. E. (2001). The influence of culture, community, and the nested-self in the stress process: Advancing conservation of resources theory. Applied Psychology: An International Review, 50, 337-421.

Hoffman, B. J., Blair, C. A., Meriac, J. P., \& Woehr, D. J. (2007). Expanding the criterion domain? A quantitative review of the OCB literature. Journal of Applied Psychology, 92, 555566.

Hopkins, B. (2014). Explaining variations in absence rates: Temporary and agency workers in the food manufacturing sector. Human Resource Management Journal, 24, 227-240. 
*Howard, K. J., Mayer, T. G., \& Gatchel, R. J. (2009). Effects of presenteeism in chronic occupational musculoskeletal disorders: stay at work is validated. Journal of Occupational and Environmental Medicine, 51, 724-31.

Howell, D. (2006). Statistical methods for psychology. Belmont, CA: Wadsworth.

Hu, L. T., \& Bentler, P. M. (1998). Fit indices in covariance structure modelling: Sensitivity to underparameterized model misspecification. Psychological Methods, 3, 424-453.

Humphrey, S. E., Nahrgang, J. D., \& Morgeson, F. P. (2007). Integrating motivational, social, and contextual work design features: A meta-analytic summary and theoretical extension of the work design literature. Journal of Applied Psychology, 92, 1332-1356.

Hunter, J. E., \& Schmidt, F. L. (1990). Methods of meta-analysis: Correcting error and bias in research findings. Newbury Park, CA: Sage.

Hunter, J. E., \& Schmidt, F. L. (2004). Methods of meta-analysis: Correcting error and bias in research findings (2nd ed.). Thousand Oaks, CA: Sage.

*Janssens, H., Clays, E., De Clercq, B., De Bacquer, D., \& Braeckman, L. (2013). the relation between presenteeism and different types of future sickness absence. Journal of Occupational Health, 55, 132-141.

*Janssens, H., Clays, E., Kittel, F., De Bacquer, D., Casini, A., \& Braeckman, L. (2012). The association between body mass index class, sickness absence, and presenteeism. Journal of Occupational and Environmental Medicine, 54, 604-609.

*Jena, A. B., Baldwin, D. C., Daugherty, S. R., Meltzer, D. O., \& Arora, V. M. (2010). Presenteeism among resident physicians. Journal of American Medical Association, 304, $1166-1168$.

*Johansen, V. (2012). Sickness presenteeism in Norway and Sweden. Nordic Journal of Social Research, 3, 1-15. 
Johansen, V., Aronsson, G., \& Marklund, S. (2014). Positive and negative reasons for sickness presenteeism in Norway and Sweden: A cross-sectional survey. BMJ Open, 4, e004123.

*Johansson, G., \& Lundberg, I. (2004). Adjustment latitude and attendance requirements as determinants of sickness absence or attendance. Empirical tests of the illness flexibility model. Social Science \& Medicine (1982), 58, 1857-1868.

Johns, G. (1997). Contemporary research on absence from work: Correlates, causes, and consequences. International Review of Industrial and Organizational Psychology, 12, 115174.

Johns, G. (2008). Absenteeism and presenteeism: Not at work or not working well. In C. L. Cooper, \& J. Barling (Eds.), The Sage handbook of organizational behavior (Vol. 1, pp. 160177). London: Sage.

Johns, G. (2010). Presenteeism in the workplace: A review and research agenda. Journal of Organizational Behavior, 31, 519-542.

*Johns, G. (2011). Attendance dynamics at work: The antecedents and correlates of presenteeism, absenteeism, and productivity loss. Journal of Occupational Health Psychology, 16, 483-500.

Johns, G. (2012). Presenteeism: A short history and a cautionary tale. In J. Houdmont, S. Leka, \& R.R. Sinclair (Eds.), Contemporary occupational health psychology: Global perspectives on research and practice (Vol. 2, pp. 204-220). Chichester, UK: Wiley-Blackwell.

Johns, G., \& Al Hajj, R. (2014, April). Time lost versus frequency measures of absenteeism: Does one really reflect health and the other work attitudes? Paper presented at the conference of the European Academy of Occupational Health Psychology, London. 
Johns, G., \& Miraglia, M. (2015). The reliability, validity, and accuracy of self-reported absenteeism from work: A meta-analysis. Journal of Occupational Health Psychology, 20, 114.

Johns, G., \& Xie, J. L. (1998). Perceptions of absence from work: People's Republic of China versus Canada. Journal of Applied Psychology, 83, 515-530.

Johnson, J. V., \& Hall, E. M. (1988). Job strain, work place social support, and cardiovascular disease: A cross-sectional study of a random sample of the Swedish working population. American Journal of Public Health, 78, 1336-1342.

Johnson, J. V., Hall, E. M., \& Theorell, T. (1989). Combined effects of job strain and social isolation on cardiovascular disease morbidity and mortality in a random sample of the Swedish male working population. Scandinavian Journal of Work, Environment and Health, $15,271-279$.

*Jourdain, G., \& Vézina, M. (2013). How psychological stress in the workplace influences presenteeism propensity: A test of the demand-control-support model. European Journal of Work and Organizational Psychology, 23, 483-496.

Karasek, R. (1979). Job demands, job decision latitude and mental strain: Implications for job redesign. Administrative Science Quarterly, 24 , 285-306.

Karasek, R., \& Theorell, T. (1990). Healthy work: Stress, productivity, and the reconstruction of working life. New York, NY: Basic Books.

Karasek, R., Brisson, C., Kawakami, N., Houtman, I. L. D., Bongers, P. M., \& Amick, B. C., III. (1998). The job content questionnaire (JCQ): An instrument for internationally comparative assessments of psychosocial job characteristics. Journal of Occupational Health Psychology, $3,322-355$. 
*Karoly, P., Ruehlman, L. S., \& Okun, M. A. (2013). Psychosocial and demographic correlates of employment vs. disability status in a national community sample of adults with chronic pain: Toward a psychology of pain presenteeism. Pain Medicine, 14, 1698-1707.

Keim, A. C., Landis, R. S., Pierce, C. A., \& Earnest, D. R. (2014). Why do employees worry about their jobs? A meta-analytic review of predictors of job insecurity. Journal of Occupational Health Psychology, 19, 269-290.

Kessler, R. C., Barber, C., Beck, A., Berglund, P., Cleary, P. D., McKenas, D., ... Wang, P. (2003). The World Health Organization Health and Work Performance Questionnaire (HPQ). Journal of Occupational and Environmental Medicine, 45, 156-174.

*Kivimäki, M., Head, J., Ferrie, J. E., Hemingway, H., Shipley, M. J., Vahtera, J., \& Marmot, M. G. (2005). Working while ill as a risk factor for serious coronary events: The Whitehall II study. American Journal of Public Health, 95, 98-102.

Kivimäki, M., Vahtera, J., Pentti, J., \& Ferrie, J. E. (2000). Factors underlying the effect of organizational downsizing on health of employees: Longitudinal cohort study. British Medical Journal, 320, 971-975.

*Koneczy, B. E. (2012). Working despite illness: The relationship between employee demographics and job stressors in mental health organizations (Doctoral disertation). Retrived from ProQuest Dissertations and Theses database (UMI No. 3511209).

Kossek, E. E., \& Ozeki, C. (1999). Bridging the work-family policy and productivity gap: A literature review. Community, Work \& Family, 2, 7- 32.

Krohne, K., \& Magnussen, L. H. (2011). Go to work or report sick? A focus group study on decisions of sickness presence among offshore catering section workers. BMC Research Notes, 4, 70-77. 
*Leineweber, C., Westerlund, H., Hagberg, J., Svedberg, P., Luokkala, M., \& Alexanderson, K. (2011). Sickness presenteeism among Swedish police officers. Journal of Occupational Rehabilitation, 21, 17-22.

*Leineweber, C., Westerlund, H., Hagberg, J., Svedberg, P., \& Alexanderson, K. (2012). Sickness presenteeism is more than an alternative to sickness absence: Results from the population-based SLOSH study. International Archives of Occupational and Environmental Health, 85, 905-914.

LePine, J. A., Podsakoff, N. P., \& LePine, M. A. (2005). A meta-analytic test of the challenge stressor - hindrance stressor framework: An explanation for inconsistent relationships among stressors and performance. Academy of Management Journal, 48, 764-775.

Lerner, D., Amick, B. C., Rogers, W. H., Malspeis, S., Bungay, K., \& Cynn, D. (2001). The work limitations questionnaire. Medical Care, 39, 72-85.

*Linton, S. J., \& Buer, N. (1995). Working despite pain: Factors associated with work attendance versus dysfunction. International Journal of Behavioral Medicine, 2, 252-62.

Lipsey, M. W., \& Wilson, D. B. (2001). Practical meta-analysis. Thousand Oaks, CA: Sage.

*Löve, J., Grimby-Ekman, A., Eklöf, M., Hagberg, M., \& Dellve, L. (2010). “Pushing oneself too hard": Performance-based self-esteem as a predictor of sickness presenteeism among young adult women and men-a cohort study. Journal of Occupational and Environmental Medicine, 52, 603-9.

*Lu, L., Cooper, C. L., \& Lin, H. Y. (2013). A cross-cultural examination of presenteeism and supervisory support. Career Development International, 18, 440-456.

*Lu, L., Lin, H. Y., \& Cooper, C. L. (2013). Unhealthy and present: Motives and consequences of the act of presenteeism among Taiwanese employees. Journal of Occupational Health Psychology, 18, 406-416. 
Luchman, J. N., \& González-Morales, M. G. (2013). Demands, control, and support: A metaanalytic review of work characteristics interrelationships. Journal of Occupational Health Psychology, 18, 37-52.

*MacGregor, J. N., Cunningham, J. B., \& Caverley, N. (2008). Factors in absenteeism and presenteeism: Life events and health events. Management Research News, 31, 607-615.

Macey, W. H., \& Schneider, B. (2008). The meaning of employee engagement. Industrial and Organizational Psychology, 1, 3-30.

*Maksymowych, W. P., Gooch, K. L., Wong, R. L., Kupper, H., \& van der Heijde, D. (2010). Impact of age, sex, physical function, health-related quality of life, and treatment with adalimumab on work status and work productivity of patients with ankylosing spondylitis. The Journal of Rheumatology, 37, 385-392.

Mastekaasa, A. (2013). Unionization and certified sickness absence: Norwegian evidence. Industrial \& Labor Relations Review, 66, 117-141.

McKevitt, C., Morgan, M., Dundas, R., \& Holland, W. W. (1997). Sickness absence and "working through" illness: A comparison of two professional groups. Journal of Public Health Medicine, 19, 295-300.

Meyer, J. P., Maltin, E. R., \& Thai, S. (2012) Employee commitment and well-being. In J. Houdmont, S. Leka, \& R.R. Sinclair (Eds.), Contemporary occupational health psychology: Global perspectives on research and practice (Vol. 2, pp. 19-35). Chichester, UK: WileyBlackwell.

Mostert, K. (2009). The balance between work and home: The relationship between work and home demands and ill health of employed females. South African Journal of Industrial Psychology, 35, 1-8. 
Munir, F., Leka, S., \& Griffiths, A. (2005). Dealing with self-management of chronic illness at work: Predictors for self-disclosure. Social Science \& Medicine, 60, 1397-1407.

*Munir, F., Yarker, J., \& Haslam, C. (2008). Sickness absence management: Encouraging attendance or "risk-taking" presenteeism in employees with chronic illness? Disability \& Rehabilitation, 30, 1461-1472.

Muthén, L., \& Muthén, B. O (2012). Mplus user’s guide. Los Angeles, CA: Muthén and Muthén.

Nelson, D. L., \& Burke, R. J. (2002). A framework for examining gender, work stress, and health. In D. L. Nelson, \& R. J. Burke (Eds.), Gender, work stress, and health (pp. 1-14). Washington, DC: American Psychological Association.

Ng, T. W. H., \& Feldman, D. C. (2008). Long work hours: A social identity perspective on metaanalysis data. Journal of Organizational Behavior, 29, 853-880.

*Ng, Y. G., Tamrin, S. B. M., Yik, W. M., Yusoff, I. S. M., \& Mori, I. (2014). The prevalence of musculoskeletal disorder and association with productivity loss: A preliminary study among labour intensive manual harvesting activities in oil palm plantation. Industrial Health, 52, 7885.

Niven, K., \& Ciborowska, N. (2015). The hidden dangers of attending work while unwell: A survey study of presenteeism among pharmacists. International Journal of Stress Management, 22, 207-221.

*Nyberg, A., Westerlund, H., Magnusson Hanson, L. L., \& Theorell, T. (2008). Managerial leadership is associated with self-reported sickness absence and sickness presenteeism among Swedish men and women. Scandinavian Journal of Public Health, 36, 803-11.

O’Leary-Kelly, A. M., Bowes-Sperry, L., Bates, C. A., \& Lean, E. R. (2009). Sexual harassment at work: A decade (plus) of progress. Journal of Management, 35, 503-536. 
Ones, D. S., Viswesvaran, C., \& Schmidt, F. L. (2003). Personality and absenteeism: A metaanalysis of integrity tests. European Journal of Personality, 17, S19-S38.

Parasuraman, S., \& Simmers, C. A. (2001). Type of employment, work-family conflict and wellbeing: A comparative study. Journal of Organizational Behavior, 22, 551-568.

Park, H. I., Jacob, A. C., Wagner, S. H. \& Baiden, M. (2014). Job control and burnout: A metaanalytic test of the conservation of resources model. Applied Psychology: An International Review, 63, 607-642.

Pauly, M. V., Nicholson, S., Polsky, D., Berger, M. L., \& Sharda, C. (2008). Valuing reductions in on-the-job illness: Presenteeism from managerial and economic perspectives. Health Economics, 17, 469-485.

Patton, E., \& Johns, G. (2011, August). Gender differences in absenteeism: A meta-analysis. Paper presented at the Academy of Management annual meeting, San Antonio, Texas.

Patton, E., \& Johns, G. (2012). Sex or gender? The enigma of women's elevated absenteeism. In S. Fox \& T. R. Lituchy (Eds.), Gender and the dysfunctional workplace (pp. 149-163). Cheltenham, UK: Edward Elgar.

Peterson, R. A., \& Brown, S. P. (2005). On the use of beta coefficients in meta-analysis. Journal of Applied Psychology, 90, 175-181.

Pfeffer, J. (1998). The human equation: Building profits by putting people first. Boston, MA: Harvard Business School Press.

Pohling, R., Buruck, G., Jungbauer, K.-L., \& Leiter, M. P. (in press). Work-related factors of presenteeism: The mediating role of mental and physical health. Journal of Occupational Health Psychology. Advance online publication. http://dx.doi.org/10.1037/a0039670

Quazi, H. A. (2013). Presenteeism. The invisible cost to organizations. Basingstoke, UK: Palgrave Macmillan. 
*Raak, R., \& Raak, A. (2003). Work attendance despite headache and its economic impact: A comparison between two workplaces. Headache, 43, 1097-1101.

Ramsey, R. (2006). "Presenteeism” a new problem in the workplace. Supervision, 67(8), 14-17.

*Rantanen, I., \& Tuominen, R. (2011). Relative magnitude of presenteeism and absenteeism and work-related factors affecting them among health care professionals. International Archives of Occupational and Environmental Health, 84, 225-230.

Robbins, J. M., Ford, M. T., \& Tetrick, L. E. (2012). Perceived unfairness and employee health: A meta-analytic integration. Journal of Applied Psychology, 97, 235-272.

Rodin, J., \& Ickovics, J. R. (1990). Women's Health: Review and research agenda as we approach the 21st century. American Psychologist, 45, 1018-1034.

Roe, R. A., \& van Diepen, B. (2011). Employee health and presenteeism: The challenge for human resource management. In A-S. Antoniou \& C. Cooper (Eds.), New Directions in organizational psychology and behavioral medicine (pp. 239-258). Farnham, UK: Gower.

*Rogerson, W. T. (2005). Absenteeism and presenteeism as related to self-reported health status and health beliefs of tennessee safety and health professionals (Doctoral dissertation). Retrived from ProQuest Dissertations and Theses database (UMI No. 3205797).

Rosenthal, R., \& DiMatteo, M. R. (2001). Meta-analysis: Recent developments in quantitative methods for literature reviews. Annual Review of Psychology, 52, 59-82.

Ross, C. E., Mirowsky, J., \& Goldsteen, K. (1990). The impact of the family on health: The decade in review. Journal of Marriage and Family, 52, 1059-1078.

*Rosvold, E. O., \& Bjertness, E. (2001). Physicians who do not take sick leave: Hazardous heroes? Scandinavian Journal of Public Health, 29, 71-75. 
*Sanderson, K., Tilse, E., Nicholson, J., Oldenburg, B., \& Graves, N. (2007). Which presenteeism measures are more sensitive to depression and anxiety? Journal of Affective Disorders, 101, 65-74.

*Sang, X. (2013). Occupational stress, well-being, and work outcomes amongst Chinese manufacturing workers: Testing an extension of the job demands-resources model (Doctoral dissertation). University of New South Wales, Sydney, Australia.

Scott, K. D., \& Taylor, G. S. (1985). An examination of conflicting findings on the relationship between job satisfaction and absenteeism: A meta-analysis. Academy of Management Journal, 28, 599-612.

Schaufeli, W. B., \& Bakker, A. B. (2004). Job demands , job resources, and their relationship with burnout and engagement: A multi-sample study. Journal of Organizational Behavior, $315,293-315$.

Schaufeli, W., \& Taris, T. (2014). A critical review of the job demands-resources model: Implications for improving work and health. In. G. Bauer \& O. Hämmig (Eds.), Bridging occupational, organizational and public health (pp. 43-68). Dordrecht, Netherlands: Springer.

Schultz, A. B., \& Edington, D. W. (2007). Employee health and presenteeism: A systematic review. Journal of Occupational Rehabilitation, 17, 547-579.

*Senden, M. G., Løvseth, L. T., Schenck-Gustafsson, K., \& Fridner, A. (2013). What makes physicians go to work while sick: A comparative study of sickness presenteeism in four European countries (HOUPE). Swiss Medical Weekly, 143, 1-6.

Shoss, M. K., \& Penny, L. M. (2012). The economy and absenteeism: A macro-level study. Journal of Applied Psychology, 97, 881-889.

*Skerjanc, A., \& Dodic Fikfak, M. (2014). Sickness presence among disabled workers at the University Medical Centre Ljubljana. Zdrav Var, 53, 277-282 
Sparks, K., Cooper, C., Fried, Y., \& Shirom, A. (1997). The effects of hours of work on health: A meta-analytic review. Journal of Occupational and Organizational Psychology, 70, 391408.

Snir, R., \& Harpaz, I. (2012). Beyond workaholism: Towards a general model of heavy work investment. Human Resource Management Review, 22, 232-243.

Sobel, M. E. (1982). Asymptotic confidence intervals for indirect effects in structural equation models. Sociological Methodology, 13, 290-312.

Sterne, J. A., \& Egger, M. (2005). Regression methods to detect publication bias and other bias in meta-analysis. In H. R. Rothstein, A. J. Sutton, \& M. Borenstein (Eds.), Publication bias in meta-analysis: Prevention, assessment, and adjustments (pp. 99-110). Chichester, UK: Wiley.

Sterne, J. A., Gavaghan, D., \& Egger, M. (2005). The funnel plot. In H. R. Rothstein, A. J. Sutton, \& M. Borenstein (Eds.), Publication bias in meta-analysis: Prevention, assessment, and adjustments (pp. 75-98).Chichester, UK: Wiley.

*Taloyan, M., Aronsson, G., Leineweber, C., Magnusson Hanson, L., Alexanderson, K., \& Westerlund, H. (2012). Sickness presenteeism predicts suboptimal self-rated health and sickness absence: A nationally representative study of the Swedish working population. PLoS ONE, 7, 1-8.

Taylor, P., Cunningham, I., Newsome, K., \& Scholarios, D. (2010). 'Too scared to go sick'reformulating the research agenda on sickness absence. Industrial Relations Journal, 41, 270288.

Ten Brummelhuis, L. L., Haar, J. M., \& Van der Lippe, T. (2010). Crossover of distress due to work and family demands in dual-earner couples: A dyadic analysis. Work and Stress, 24, $324-341$. 
Ten Brummelhuis, L. L., Ter Hoeven, C. L., De Jong, M. D. T., \& Peper, B. (2013). Exploring the linkage between the home domain and absence from work: Health, motivation, or both? Journal of Organizational Behavior, 34, 273-290.

Tetrick, L. E., Slack, K. J., Da Silva, N., \& Sinclair, R. R. (2000). A comparison of the stressstrain process for business owners and nonowners: Differences in job demands, emotional exhaustion, satisfaction, and social support. Journal of Occupational Health Psychology, 5, 464-476.

*Tetrick, L. E., \& Haimann, C. R. (2013). Occupational demands, environmental resources, and personal resources effects on presenteeism and healt. In A. M. Rossi, J. A. Meurs, \& P. L. Perrewé (Eds.), Improving employee health and well-being (pp. 25-34). Charlotte, NC: Information Age Publishing.

* Thun, S., Fridner, A., Minucci, D., \& Løvseth, L. T. (2014). Sickness present with signs of burnout: The relationship between burnout and sickness presenteeism among university hospital physicians in four European countries. Scandinavian Psychologist, 1, e5.

Turpin, R. S., Ozminkowski, R. J., Sharda, C. E., Collins, J. J., Berger, M. L., Billotti, G. M., ... Nicholson, S. (2004). Reliability and validity of the Stanford Presenteeism Scale. Journal of Occupational and Environmental Medicine, 46, 1123-1133.

Twain, M. (1892). The American claimant. New York, NY: Oxford University Press.

Väänänen A., Toppinen-Tanner, S., Kalimo, R., Mutanen, P., Vahtera, J. \& Peiró, J. M. (2003). Job characteristics, physical and psychological symptoms and social support as antecedents of sickness absences in men and women in the private industrial sector. Social Science \& Medicine, 57, 807-824. 
Vacha-Haase, T. (1998). Reliability generalization: Exploring variance in measurement error affecting score reliability across studies. Educational and Psychological Measurement, 58, 620.

Van der Doef, M., \& Maes, S. (1999). The Job Demand-Control (-Support) Model and psychological well-being: A review of 20 years of empirical research. Work \& Stress, 13, 87114.

Van der Heijden, B. I. J. M., Demerouti, E., Bakker, A. B., \& The NEXT Study Group coordinated by Hasselhorn, H. M. (2008). Work-home interference among nurses: Reciprocal relationships with job demands and health. Journal of Advanced Nursing, 62, 572-584.

*Vera-Calzaretta, A. (2013). Why do health care workers report to work when they are sick? Correlates of sick presenteeism among Chilean health system workers. Unpublished manuscript, University of Chile, Santiago, Chile.

Viswesvaran, C., \& Ones, D. S. (2000). Measurement error in "big five factors" personality assessment: Reliability generalization across studies and measures. Educational and Psychological Measurement, 60, 224-235.

Viswesvaran, C., \& Ones, D. S. (1995). Theory testing: Combining psychometric meta-analysis and structural equations modeling. Personnel Psychology, 48, 865-885.

*Voss, M., Floderus, B., \& Diderichsen, F. (2004). How do job characteristics, family situation, domestic work, and lifestyle factors relate to sickness absence? A study based on Sweden post. Journal of Occupational and Environmental Medicine, 46, 1134-1143.

Wang, F., Zhang, L., Zhang, Y., Zhang, B., He, Y., Xie S.,... Tse. L. A. (2014). Meta-analysis on night shift work and risk of metabolic syndrome. Obesity Reviews, 1-12.

Wanous, J. P., Reichers, A. E., \& Hudy, M. J. (1997). Overall job satisfaction: How good are single-item measures? Journal of Applied Psychology, 82, 247-252. 
Wężyk, A., \& Merecz, D. (2013). Prezentyzm-(nie) nowe zjawisko w środowisku pracy. Medycyny Pracy, 64, 847-861.

Widera, E., Chang, A., \& Chen, H. L. (2010). Presenteeism: A public health hazard. Journal of General Internal Medicine, 25, 1244-1247.

Willness, C. R., Steel, P., \& Lee, K. (2007). A meta-analysis of the antecedents and consequences of workplace sexual harassment. Personnel Psychology, 60, 127-162.

Xanthopoulou, D., Bakker, A. B., Demerouti, E., \& Schaufeli, W. B. (2009). Work engagement and financial returns: A diary study on the role of job and personal resources. Journal of Occupational and Organizational Psychology, 82, 183-200. 
Table 1

Meta-analyses for the correlates of presenteeism

\begin{tabular}{|c|c|c|c|c|c|c|c|c|c|c|}
\hline \multicolumn{2}{|c|}{ Meta-analysis } & $K$ & $N$ & $\bar{r}$ & $S D \cdot \bar{r}$ & $\rho$ & $S D_{\rho}$ & $\%$ var. & $80 \% \mathrm{CV}$ & $95 \% \mathrm{CI}$ \\
\hline \multicolumn{11}{|c|}{ Health, absenteeism, performance } \\
\hline 1. & Health status & 67 & 125,345 & -.26 & .12 & -.31 & .17 & 2.37 & $-.53,-.09$ & $-.32,-.31$ \\
\hline 1a. & Without studies inferring/dichotomizing presenteeism & 57 & 120,843 & -.27 & .11 & -.33 & .16 & 2.60 & $-.53,-.13$ & $-.33,-.32$ \\
\hline 1b. & Without EWCS & 23 & 84,600 & -.30 & .11 & -.39 & .16 & 1.56 & $-.59,-.19$ & $-.40,-.39$ \\
\hline 1c. & Only EWCS & 34 & 36,243 & -.19 & .06 & -.22 & .05 & 29.11 & $-.28,-.15$ & $-.23,-.20$ \\
\hline 2. & Mental health ${ }^{\text {a }}$ & 14 & 25,885 & -.05 & .10 & -.05 & .12 & 5.82 & $-.20, .09$ & $-.07,-.04$ \\
\hline $2 \mathrm{a}$. & Without studies inferring presenteeism ${ }^{a}$ & 6 & 22,769 & -.06 & .06 & -.07 & .08 & 6.37 & $-.17, .03$ & $-.09,-.06$ \\
\hline $2 b$. & Without Hansen \& Andersen, $2008^{\text {a }}$ & 5 & 11,499 & -.11 & .05 & -.13 & .07 & 11.43 & $-.22,-.04$ & $-.15,-.11$ \\
\hline 3. & Depression & 40 & 49,166 & .18 & .12 & .20 & .13 & 5.13 & $.03, .37$ & $.19, .21$ \\
\hline 3a. & Without studies inferring presenteeism & 37 & 46,588 & .20 & .09 & .22 & .10 & 8.13 & $.09, .35$ & $.21, .23$ \\
\hline $3 b$. & Without EWCS & 3 & 10,345 & .32 & .10 & .37 & .11 & 2.42 & $.22, .51$ & $.35, .39$ \\
\hline $3 \mathrm{c}$. & Only EWCS & 34 & 36,243 & .16 & .06 & .18 & .05 & 29.02 & $.11, .25$ & $.17, .19$ \\
\hline 4. & Absenteeism ${ }^{a}$ & 55 & 84,335 & .22 & .13 & .35 & .21 & 3.42 & $.08, .62$ & $.34, .36$ \\
\hline 4a. & Without studies dichotomizing presenteeism ${ }^{a}$ & 52 & 81,288 & .22 & .13 & .36 & .21 & 3.30 & $.09, .63$ & $.35, .37$ \\
\hline 4b. & Without EWCS a & 18 & 45,045 & .29 & .10 & .50 & .13 & 5.05 & $.33, .67$ & $.49, .51$ \\
\hline $4 c$. & Only EWCS a & 34 & 36,243 & .13 & .11 & .21 & .17 & 7.00 & $-.01, .42$ & $.19, .22$ \\
\hline 5. & Productivity loss ${ }^{a}$ & 5 & 1,535 & .21 & .09 & .28 & .21 & 13.68 & $.00, .55$ & $.20, .35$ \\
\hline 6. & Performance ratings & 4 & 1,743 & -.01 & .05 & -.01 & .03 & 77.12 & $-.05, .03$ & $-.07, .04$ \\
\hline \multicolumn{11}{|c|}{ Constraints on absenteeism } \\
\hline 7. & Strict absence policies ${ }^{a}$ & 5 & 5,730 & .27 & .05 & .39 & .08 & 20.41 & $.29, .49$ & $.35, .42$ \\
\hline 8. & Job insecurity ${ }^{a}$ & 44 & 69,978 & .07 & .06 & .08 & .08 & 13.98 & $-.02, .17$ & $.07, .09$ \\
\hline $8 a$. & Only positive values ${ }^{a}$ & 33 & 56,905 & .09 & .05 & .11 & .06 & 18.88 & $.03, .19$ & $.10, .12$ \\
\hline $8 b$. & Without EWCS a & 10 & 33,735 & .11 & .04 & .15 & .06 & 14.77 & $.08, .22$ & $.13, .17$ \\
\hline $8 \mathrm{c}$. & Only EWCS & 34 & 36,243 & .03 & .05 & .03 & .04 & 36.49 & $-.03, .09$ & $.02, .04$ \\
\hline 9. & Employment form ( 1 = permanent, $2=$ temporary $)$ & 44 & 76,584 & -.01 & .07 & -.01 & .08 & 12.77 & $-.11, .10$ & $-.02, .00$ \\
\hline 9a. & Without EWCS & 10 & 40341 & .00 & .08 & .00 & .09 & 3.794 & $-.12, .12$ & $-.01, .01$ \\
\hline $9 \mathrm{~b}$. & Only EWCS & 34 & 36,243 & -.02 & .04 & -.02 & .05 & 45.91 & $-.09, .04$ & $-.04,-.01$ \\
\hline
\end{tabular}




\begin{tabular}{|c|c|c|c|c|c|c|c|c|c|c|}
\hline \multicolumn{11}{|c|}{ Financial situation } \\
\hline 10. & Income & 47 & 74,247 & -.02 & .07 & -.02 & .08 & 11.33 & $-.12, .08$ & $-.03,-.01$ \\
\hline 10a. & Without studies inferring/dichotomizing presenteeism & 42 & 71,769 & -.02 & .07 & -.01 & .08 & 10.79 & $-.12, .08$ & $-.03,-.01$ \\
\hline $10 \mathrm{~b}$. & Without EWCS & 8 & 35,526 & -.05 & .07 & -.06 & .08 & 4.01 & $-.17, .05$ & $-.07,-.05$ \\
\hline $10 \mathrm{c}$. & Only EWCS & 34 & 36,243 & .02 & .05 & .02 & .05 & 33.50 & $-.04, .08$ & $.00, .03$ \\
\hline 11. & Personal financial difficulties & 43 & 51,509 & .09 & .06 & .10 & .06 & 22.28 & $.02, .18$ & $.09, .11$ \\
\hline 11a. & Without EWCS & 9 & 15,266 & .11 & .07 & .15 & .09 & 12.78 & $.04, .26$ & $.13, .17$ \\
\hline $11 \mathrm{~b}$. & Only EWCS & 34 & 36,243 & .08 & .05 & .09 & .05 & 35.23 & $.03, .15$ & $.07, .10$ \\
\hline 12. & Ease of replacement ${ }^{\text {a }}$ & 8 & 8,215 & -.09 & .06 & -.13 & .06 & 90.79 & $-.21,-.05$ & $-.16,-.10$ \\
\hline \multicolumn{11}{|c|}{ Job demands and experienced stress } \\
\hline \multicolumn{11}{|c|}{ Role demands } \\
\hline 13. & Workload $^{\text {a }}$ & 7 & 3,238 & .20 & .04 & .28 & .01 & 98.08 & $.25, .27$ & $.23, .32$ \\
\hline 14. & Understaffing & 5 & 2,674 & .18 & .09 & .25 & .11 & 22.95 & $.11, .37$ & $.20, .30$ \\
\hline 15. & Physical demands a & 41 & 52,372 & .10 & .06 & .13 & .07 & 20.70 & $.04, .22$ & $.12, .14$ \\
\hline $15 \mathrm{a}$. & Without EWCS a & 7 & 16,129 & .08 & .04 & .11 & .03 & 45.12 & $.07, .14$ & $.09, .13$ \\
\hline $15 \mathrm{~b}$. & Only EWCS ${ }^{b}$ & 34 & 36,243 & .10 & .07 & .18 & .11 & 19.54 & $.04, .32$ & $.16, .20$ \\
\hline 16. & Difficult patients/clients & 35 & 36,501 & .08 & .05 & .09 & .04 & 43.39 & $.04, .14$ & $.08, .10$ \\
\hline 17. & Number of patients & 4 & 2,447 & .14 & .05 & .20 & .03 & 75.49 & $.16, .24$ & $.15, .25$ \\
\hline 18. & Supervisory duties & 45 & 66,074 & .04 & .06 & .05 & .06 & 21.18 & $-.03, .12$ & $.04, .06$ \\
\hline $18 \mathrm{a}$. & Without studies inferring presenteeism & 43 & 63,979 & .03 & .05 & .04 & .05 & 31.74 & $-.02, .10$ & $.03, .05$ \\
\hline $18 \mathrm{~b}$. & $\begin{array}{l}\text { Without EWCS, Hansen \& Andersen, 2008, and } \\
\text { Leineweber et al., } 2011\end{array}$ & 7 & 4,673 & .12 & .06 & .17 & .08 & 35.15 & $.08, .27$ & $.13, .21$ \\
\hline $18 c$. & Only EWCS & 34 & 36,243 & .04 & .04 & .08 & .02 & 68.70 & $.01, .07$ & $.03, .05$ \\
\hline 19. & Role conflict & 35 & 38,973 & .04 & .04 & .05 & .04 & 44.42 & $-.00, .10$ & $.04, .06$ \\
\hline 20. & Role ambiguity & 35 & 36,480 & -.02 & .04 & -.02 & .02 & 69.14 & $-.05, .01$ & $-.03,-.01$ \\
\hline \multicolumn{11}{|c|}{ Time demands } \\
\hline 21. & Overtime & 35 & 52,451 & .14 & .05 & .15 & .05 & 36.17 & $.10, .21$ & $.14, .16$ \\
\hline 22. & Work hours & 40 & 52,451 & .09 & .05 & .11 & .05 & 30.60 & $.05, .17$ & $.10, .16$ \\
\hline 22a. & Without studies inferring presenteeism & 38 & 51,907 & .09 & .05 & .11 & .05 & 27.43 & $.05, .17$ & $.10, .12$ \\
\hline $22 b$. & Without EWCS & 4 & 15,664 & .05 & .04 & .06 & .04 & 17.18 & $.01, .12$ & $.04, .08$ \\
\hline $22 \mathrm{c}$. & Only EWCS & 34 & 36,243 & .11 & .04 & .12 & .04 & 44.75 & $.07, .17$ & $.11, .13$ \\
\hline 23. & Time pressure ${ }^{a}$ & 47 & 55,550 & .14 & .07 & .16 & .07 & 17.42 & $.07, .25$ & $.15, .17$ \\
\hline
\end{tabular}




\begin{tabular}{|c|c|c|c|c|c|c|c|c|c|c|}
\hline $23 a$. & Without studies dichotomizing presenteeism $^{a}$ & 45 & 55,131 & .14 & .07 & .18 & .07 & 20.29 & $.09, .27$ & $.17, .19$ \\
\hline $23 b$. & Without EWCS a & 11 & 18,888 & .21 & .04 & .24 & .03 & 42.67 & $.20, .28$ & $.23, .26$ \\
\hline $23 \mathrm{c}$. & Only EWCS b & 34 & 36,243 & .11 & .05 & .14 & .06 & 33.12 & $.07, .21$ & $.13, .15$ \\
\hline 24. & Shift work & 37 & 37,090 & -.01 & .04 & -.01 & .03 & 61.44 & $-.04, .03$ & $-.02, .01$ \\
\hline $24 a$. & Without studies inferring presenteeism & 35 & 36,919 & .00 & .04 & -.01 & .03 & 59.43 & $-.04, .03$ & $-.02, .01$ \\
\hline 25. & Overall job demands ${ }^{b}$ & 46 & 67,544 & .12 & .07 & .16 & .09 & 13.89 & $.05, .27$ & $.15, .17$ \\
\hline $25 \mathrm{a}$. & Without EWCS b & 12 & 31,301 & .15 & .06 & .19 & .10 & 6.05 & $.06, .31$ & $.17, .20$ \\
\hline $25 b$. & Only EWCS ${ }^{\mathrm{b}}$ & 34 & 36,243 & .09 & .05 & .13 & .06 & 34.19 & $.05, .20$ & $.11, .14$ \\
\hline 26. & Experienced stress ${ }^{\text {a }}$ & 44 & 75,592 & .20 & .08 & .25 & .10 & 7.28 & $.10, .12$ & $.24, .25$ \\
\hline $26 a$. & $\begin{array}{l}\text { Without EWCS, } 1 \text { study inferring presenteeism, } \\
\text { Leineweber et al., 2011, and Heponiemi et al., } 2010^{\text {a }}\end{array}$ & 7 & 9,039 & .28 & .13 & .33 & .18 & 3.08 & $.11, .56$ & $.31, .36$ \\
\hline $26 b$. & Only EWCS & 34 & 36,243 & .17 & .05 & .19 & .05 & 31.51 & $.13, .26$ & $.18, .20$ \\
\hline 27. & Emotional exhaustion $^{a}$ & 10 & 12,815 & .30 & .05 & .36 & .05 & 27.47 & $.30, .43$ & $.34, .38$ \\
\hline $27 \mathrm{a}$. & Without studies inferring presenteeism ${ }^{a}$ & 9 & 12,704 & .30 & .05 & .37 & .04 & 35.92 & $.31, .42$ & $.35, .38$ \\
\hline 28. & Discrimination $^{b}$ & 34 & 36,243 & .07 & .04 & .10 & .04 & 61.47 & $.06, .15$ & $.09, .12$ \\
\hline 29. & Harassment $^{\mathrm{b}}$ & 34 & 36,243 & .09 & .05 & .16 & .10 & 25.33 & $.04, .29$ & $.14, .18$ \\
\hline 30. & Abuse $^{b}$ & 34 & 36,243 & .13 & .04 & .20 & .05 & 48.60 & $.14, .26$ & $.19, .22$ \\
\hline 31. & Work to family conflict ${ }^{a}$ & 38 & 37,780 & .13 & .05 & .14 & .04 & 42.08 & $.10, .20$ & $.13, .16$ \\
\hline 31a. & Without EWCS a & 4 & 1,537 & .16 & .11 & .25 & .12 & 27.19 & $.10, .40$ & $.18, .32$ \\
\hline $31 b$. & Only EWCS & 34 & 36,243 & .12 & .04 & .14 & .03 & 48.58 & $.09, .18$ & $.13, .15$ \\
\hline 32. & Family to work conflict ${ }^{a}$ & 4 & 16,749 & .14 & .07 & .18 & .07 & 6.78 & $.09, .26$ & $.16, .19$ \\
\hline \multicolumn{11}{|c|}{ Job and personal resources } \\
\hline \multicolumn{11}{|c|}{ Job control } \\
\hline 33. & Overall control $^{\mathrm{a}}$ & 54 & 82,292 & -.02 & .09 & -.03 & .10 & 8.46 & $-.17, .10$ & $-.04,-.02$ \\
\hline $33 a$. & Without EWCS ${ }^{\text {a }}$ & 20 & 45,516 & -.08 & .06 & -.09 & .07 & 12.08 & $-.18,-.01$ & $-.10,-.08$ \\
\hline $33 b$. & Only EWCS ${ }^{b}$ & 34 & 36,243 & .05 & .06 & .07 & .09 & 24.11 & $-.04, .19$ & $.06, .09$ \\
\hline 34. & Job control ${ }^{\mathrm{a}}$ & 50 & 74,162 & -.01 & .08 & -.01 & .09 & 11.16 & $-.13, .11$ & $-.02, .00$ \\
\hline 35. & Adjustment latitude & 39 & 46,021 & -.07 & .06 & -.08 & .07 & 20.00 & $-.17, .01$ & $-.09,-.07$ \\
\hline $35 \mathrm{a}$. & Without EWCS & 5 & 9,778 & -.14 & .04 & -.19 & .04 & 40.89 & $-.23,-.14$ & $-.21,-.16$ \\
\hline $35 b$. & Only EWCS & 34 & 36,243 & -.05 & .05 & -.06 & .05 & 33.59 & $-.12, .01$ & $-.07,-.05$ \\
\hline 36. & Decision authority $^{a}$ & 37 & 40,606 & .04 & .07 & .05 & .07 & 21.28 & $-.04, .13$ & $.03, .06$ \\
\hline 37. & Participation $^{\mathrm{b}}$ & 34 & 36,243 & .02 & .06 & .03 & .07 & 24.54 & $-.06, .12$ & $.02, .04$ \\
\hline
\end{tabular}




\begin{tabular}{|c|c|c|c|c|c|c|c|c|c|c|}
\hline 38. & Work significance & 36 & 37,216 & .00 & .05 & .00 & .05 & 37.85 & $-.06, .06$ & $-.01, .01$ \\
\hline 38a. & Without EWCS $^{\mathrm{c}}$ & 2 & 840 & .01 & .03 & .02 & - & - & - & $-.08, .11$ \\
\hline $38 \mathrm{~b}$. & Only EWCS & 34 & 36,243 & -.01 & .05 & -.01 & .04 & 43.96 & $-.05, .04$ & -.02 .01 \\
\hline \multicolumn{11}{|c|}{ Collegial support } \\
\hline 39. & Colleagues support ${ }^{\mathrm{a}}$ & 42 & 54,677 & -.06 & .05 & -.07 & .05 & 29.33 & $-.14,-.01$ & $-.08,-.06$ \\
\hline 39a. & Without EWCS a & 8 & 18,434 & -.09 & .03 & -.12 & .03 & 45.96 & $-.16,-.08$ & $-.14,-.10$ \\
\hline $39 \mathrm{~b}$. & Only EWCS & 34 & 36,243 & -.05 & .05 & -.06 & .05 & 39.20 & $-.13, .01$ & $-.08,-.05$ \\
\hline 40. & Relationship with colleagues a & 39 & 39,158 & -.05 & .05 & -.05 & .05 & 33.53 & $-.11, .02$ & $-.06,-.04$ \\
\hline 40a. & Without EWCS ${ }^{a}$ & 5 & 2,915 & -.12 & .08 & -.15 & .09 & 24.06 & $-.26,-.03$ & $-.19,-.10$ \\
\hline $40 \mathrm{~b}$. & Only EWCS & 34 & 36,243 & -04 & .05 & -.04 & .04 & 43.72 & $-.10, .01$ & $-.05,-.03$ \\
\hline 41. & Supervisory support ${ }^{a}$ & 49 & 56,545 & -.08 & .06 & -.10 & .06 & 26.62 & $-.17,-.02$ & $-.11,-.09$ \\
\hline 41a. & Without EWCS a & 15 & 20,302 & -.09 & .03 & -.13 & .03 & 69.68 & $-.16,-.10$ & $-.15,-.11$ \\
\hline $41 \mathrm{~b}$. & Only EWCS & 34 & 36,243 & -.07 & .06 & -.08 & .06 & 23.46 & $-.16,-.01$ & $-.10,-.07$ \\
\hline 42. & Organizational support ${ }^{a}$ & 4 & 1,275 & -.14 & .14 & -.17 & .16 & 15.18 & $-.38,-.16$ & $-.24,-.11$ \\
\hline 43. & Quality leadership ${ }^{b}$ & 36 & 53,177 & -.10 & .04 & -.13 & .05 & 28.72 & $-.20,-.06$ & $-.14,-.12$ \\
\hline $43 a$. & Without EWCS ${ }^{b}$ & 2 & 16,934 & -.07 & .01 & -.08 & .01 & 44.01 & $-.10,-.06$ & $-.10,-.06$ \\
\hline $43 b$. & Only EWCS ${ }^{b}$ & 34 & 36,243 & -.12 & .04 & -.16 & .04 & 45.68 & $-.22,-.10$ & $-.17,-.15$ \\
\hline 44. & Conscientiousness $^{\text {a }}$ & 5 & 1,658 & .04 & .06 & .05 & .05 & 75.24 & $-.01, .11$ & $-.02, .12$ \\
\hline 45. & Optimism $^{\mathrm{b}}$ & 34 & 36,243 & -.18 & .06 & -.22 & .07 & 22.80 & $-.31,-.14$ & $-.23,-.21$ \\
\hline \multicolumn{11}{|c|}{ Job attitudes and justice } \\
\hline 46. & Job satisfaction $^{\mathrm{a}}$ & 51 & 51,088 & .08 & .12 & .12 & 0.15 & 7.66 & $-.08, .32$ & $.11, .13$ \\
\hline $46 a$. & Without studies inferring/dichotomizing presenteeism ${ }^{a}$ & 46 & 49,367 & .09 & .11 & .13 & 0.14 & 8.47 & $-.05, .31$ & $.12, .14$ \\
\hline $46 \mathrm{~b}$. & Without EWCS, and Taloyan et al., 2012 ${ }^{\mathrm{a}}$ & 11 & 5,679 & .10 & .16 & .11 & 0.20 & 6.77 & $-.14, .36$ & $.08, .14$ \\
\hline 46c. & Only EWCS a & 34 & 36,243 & .13 & .04 & .18 & .041 & 50.96 & $.13, .23$ & $.17, .20$ \\
\hline 47. & Affective commitment ${ }^{b}$ & 6 & 14,644 & .16 & .11 & .20 & 0.15 & 2.82 & $.01, .39$ & $.18, .22$ \\
\hline 48. & Work engagement ${ }^{\text {ac }}$ & 3 & 1,182 & .11 & .04 & .13 & - & - & - & $.06, .21$ \\
\hline 49. & Organizational justice ${ }^{a}$ & 6 & 5,492 & -.08 & .05 & -.13 & 0.04 & 64.16 & $-.171,-.082$ & $-.17,-.09$ \\
\hline 49a. & Without studies inferring presenteeism & 5 & 5,381 & -.09 & .04 & -.13 & 0.01 & 98.66 & $-.137,-.124$ & $-.17,-.09$ \\
\hline \multicolumn{11}{|c|}{ Other variables } \\
\hline \multicolumn{11}{|c|}{ Demographics } \\
\hline 50. & Gender $(1=$ male, $2=$ female $)$ & 82 & 138,243 & .04 & .06 & .04 & .06 & 18.61 & $-.04, .12$ & $.04, .05$ \\
\hline 50a. & Without studies inferring/dichotomizing presenteeism & 66 & 123,920 & .04 & .04 & .05 & .04 & 36.81 & $.00, .10$ & $.05, .06$ \\
\hline
\end{tabular}




\begin{tabular}{|c|c|c|c|c|c|c|c|c|c|c|}
\hline $50 \mathrm{~b}$. & Without EWCS & 32 & 87,677 & .04 & .04 & .05 & .04 & 26.30 & $.00, .11$ & $.05, .06$ \\
\hline $50 \mathrm{c}$. & Only EWCS & 34 & 36,243 & .05 & .04 & .07 & .04 & 59.01 & $.02, .11$ & $.05, .08$ \\
\hline 51. & Age & 77 & 134,814 & -.03 & .08 & -.03 & .09 & 8.88 & $-.15, .08$ & $-.04,-.03$ \\
\hline 51a. & $\begin{array}{l}\text { Without studies inferring/dichotomizing presenteeism, } \\
\text { and Heponiemi et al., } 2010\end{array}$ & 61 & 104,812 & -.03 & .07 & -.04 & .08 & 12.18 & $-.13, .06$ & $-.04,-.03$ \\
\hline $51 \mathrm{~b}$. & Without EWCS & 27 & 68,569 & -.05 & .07 & -.06 & .08 & 8.70 & $-.16, .03$ & $-.07,-.05$ \\
\hline 51c. & Only EWCS & 34 & 36,243 & .01 & .05 & .01 & .06 & 32.10 & $-.07, .09$ & $-.01, .02$ \\
\hline 52. & Tenure & 46 & 41,816 & .04 & .05 & .05 & .05 & 40.39 & $-.01, .11$ & $.04, .06$ \\
\hline $52 \mathrm{a}$. & Without studies inferring/dichotomizing presenteeism & 43 & 41,286 & .04 & .05 & .05 & .04 & 42.07 & $-.01, .10$ & $.04, .06$ \\
\hline $52 b$. & Without EWCS & 9 & 5,043 & .04 & .07 & .05 & .07 & 36.85 & $-.05, .14$ & $.01, .08$ \\
\hline $52 \mathrm{c}$. & Only EWCS & 34 & 36,243 & .04 & .05 & .06 & .05 & 43.72 & $-.01, .12$ & $.05, .08$ \\
\hline 53. & Education & 53 & 91,559 & .01 & .06 & .02 & .06 & 16.76 & $-.06, .09$ & $.01, .02$ \\
\hline $53 a$. & $\begin{array}{l}\text { Without studies inferring/dichotomizing presenteeism, } \\
\text { and Heponiemi et al., } 2010\end{array}$ & 45 & 66,994 & .01 & .05 & .01 & .05 & 26.14 & $-.06, .07$ & $.001, .02$ \\
\hline $53 \mathrm{~b}$. & Without EWCS & 12 & 49,205 & .00 & .04 & .00 & .05 & 12.98 & $-.06, .06$ & $-.012, .009$ \\
\hline $53 \mathrm{c}$. & Only EWCS & 34 & 36,243 & .02 & .05 & .03 & .05 & 46.79 & $-.03, .08$ & $.01, .04$ \\
\hline \multicolumn{11}{|c|}{ Macro organizational variables } \\
\hline 54. & Sector $(1=$ private, $2=$ public $)$ & 37 & 40,357 & .02 & .04 & .02 & .04 & 47.35 & $-.03, .07$ & $.01, .03$ \\
\hline $54 \mathrm{a}$. & Without EWCS & 3 & 4,114 & .07 & .06 & .10 & .07 & 20.42 & $.01, .20$ & $.06, .15$ \\
\hline $54 \mathrm{~b}$. & Only EWCS & 34 & 36,243 & .01 & .04 & .01 & .02 & 70.31 & $-.01, .02$ & $.01, .03$ \\
\hline 55. & Organizational size & 36 & 47,730 & -.02 & .05 & -.02 & .04 & 33.77 & $-.07, .04$ & $-.03,-.01$ \\
\hline
\end{tabular}

Note. $K=$ total number of samples; $N=$ total sample size across studies; $\overline{\mathrm{r}}=$ sample-size-weighted mean of correlations; SD. $\overline{\mathrm{r}}=$ standard deviation of $\overline{\mathrm{r}} ; \rho=$ estimated population correlation; $\mathrm{SD}_{\rho}=$ standard deviation of $\rho ; \%$ var. = percent of variance accounted for by sampling and measurement error; $80 \% \mathrm{CV}=$ $80 \%$ credibility interval; $95 \% \mathrm{CI}=95 \%$ confidence interval. All the estimated population correlations are sample-size weighted and corrected for unreliability in presenteeism.

${ }^{a}$ Correlations are corrected for unreliability in the correlate, using the artifact distribution. ${ }^{\mathrm{b}}$ Correlations are individually corrected for unreliability in the correlate. ${ }^{\mathrm{c}}$ The analysis produced negative standard deviation in the corrected correlation, probably attributable to the small numbers of studies (Hunter $\&$ Schmidt, 2004). 
Table 2

Meta-analytic correlation matrix

\begin{tabular}{|c|c|c|c|c|c|c|c|c|c|c|c|}
\hline & 1. Presenteeism & 2. & 3. & 4. & 5. & 6. & 7. & 8. & 9. & 10. & 11. \\
\hline 2. Absenteeism & .36 & & & & & & & & & & \\
\hline$k$ & 52 & & & & & & & & & & \\
\hline$N$ & 81288 & & & & & & & & & & \\
\hline 3. Job satisfaction & .13 & -.19 & & & & & & & & & \\
\hline$k$ & 46 & 40 & & & & & & & & & \\
\hline$N$ & 49367 & 46572 & & & & & & & & & \\
\hline 4. Optimism & -.22 & -.21 & .36 & & & & & & & & \\
\hline$k$ & 34 & 34 & 34 & & & & & & & & \\
\hline$N$ & 36243 & 36243 & 36243 & & & & & & & & \\
\hline 5. Gender & .05 & .14 & $.06^{\mathrm{a}}$ & -.07 & & & & & & & \\
\hline$k$ & 66 & 45 & 21 & 34 & & & & & & & \\
\hline$N$ & 123920 & 63437 & 7242 & 36243 & & & & & & & \\
\hline 6. Pers. fin. diffic. & .10 & .10 & -.26 & -.28 & .04 & & & & & & \\
\hline$k$ & 43 & 36 & 38 & 34 & 34 & & & & & & \\
\hline$N$ & 51509 & 43795 & 38591 & 36243 & 36243 & & & & & & \\
\hline 7. Job insecurity & .11 & -.04 & $-.43^{b}$ & -.18 & $-.03^{\mathrm{f}}$ & .20 & & & & & \\
\hline$k$ & 33 & 36 & 94 & 34 & 39 & 38 & & & & & \\
\hline$N$ & 56905 & 36924 & 76260 & 36243 & 35643 & 38591 & & & & & \\
\hline 8. Job control & -.03 & -.07 & $.31^{\mathrm{c}}$ & .04 & .01 & -.10 & -.11 & & & & \\
\hline$k$ & 54 & 40 & 42 & 34 & 43 & 34 & 40 & & & & \\
\hline$N$ & 82292 & 46292 & 35428 & 36243 & 49839 & 36243 & 39341 & & & & \\
\hline 9. Collegial support & -.07 & -.03 & $.40^{\mathrm{d}}$ & .19 & -.01 & -.09 & -.08 & $.23^{\mathrm{c}}$ & & & \\
\hline$k$ & 42 & 37 & 100 & 34 & 36 & 34 & 35 & 30 & & & \\
\hline$N$ & 54677 & 38719 & 31966 & 36243 & 38502 & 36243 & 36480 & 110734 & & & \\
\hline 10. Sup. support & -.10 & -.09 & $.38^{\mathrm{c}}$ & .25 & .01 & -.12 & -.13 & $.30^{\mathrm{c}}$ & $.43^{\mathrm{c}}$ & & \\
\hline$k$ & 49 & 38 & 13 & 34 & 37 & 34 & 33 & 28 & 23 & & \\
\hline$N$ & 56545 & 38980 & 9069 & 36243 & 39116 & 36243 & 36786 & 111409 & 104372 & & \\
\hline
\end{tabular}




\begin{tabular}{|c|c|c|c|c|c|c|c|c|c|c|c|}
\hline & 1. Presenteeism & 2. & 3. & 4. & 5. & 6. & 7. & 8. & 9. & 10. & 11. \\
\hline 11. Health & -.33 & -.31 & $.29^{\mathrm{e}}$ & .39 & -.01 & -.22 & $-.23^{b}$ & .004 & .12 & .14 & \\
\hline$k$ & 57 & 47 & 119 & 34 & 40 & 34 & 44 & 41 & 35 & 36 & \\
\hline$N$ & 120843 & 68010 & 58762 & 36243 & 46513 & 36243 & 56934 & 51164 & 36480 & 36721 & \\
\hline 12. Job demands & .16 & .05 & $-.09^{c}$ & .09 & -.07 & -.19 & -.11 & $-.02^{\mathrm{c}}$ & $-.11^{\mathrm{c}}$ & $-.16^{\mathrm{c}}$ & -.002 \\
\hline$k$ & 46 & 37 & 49 & 34 & 37 & 34 & 34 & 101 & 33 & 32 & 37 \\
\hline$N$ & 67544 & 46069 & 33004 & 36243 & 45046 & 36243 & 36243 & 159500 & 113418 & 110137 & 48535 \\
\hline
\end{tabular}

Note . Pers. fin. diffic. $=$ Personal financial difficulties; Sup. support = Supervisory support; Gender: $1=$ Male, $2=$ Female; Harmonic $N=40,006 ;{ }^{a}$ Brush, Moch, \& Pooyan, 1987; ${ }^{\mathrm{b}}$ Cheng \& Chan, 2008; ${ }^{\mathrm{c}}$ Luchman \& González-Morales, 2013; ${ }^{\mathrm{d}}$ Chiaburu \& Harrison, 2008; ${ }^{\mathrm{e}}$ Faragher, Cass, \& Cooper, 2005; ${ }^{\mathrm{f}}$ Keim, Landis, Pierce, \& Earnest, 2014 
Table 3

Structural parameter estimates for the direct and indirect effects of variables on presenteeism and absenteeism

\begin{tabular}{lll}
\hline Variable & Presenteeism $\beta$ & Absenteeism $\beta$ \\
\hline Direct effects & & -.09 \\
\hline Job insecurity & .21 & $.01($ n.s.) \\
Personal financial difficulties & .09 & -.05 \\
Job control & -.11 & .05 \\
Job demands & .24 & .09 \\
Collegial support & -.10 & -.01 (n.s.) \\
Supervisor support & -.05 & -.07 \\
Optimism & -.21 & \\
\hline Indirect effects via job satisfaction & & .05 \\
\hline Job insecurity & -.17 & .02 \\
Personal financial difficulties & -.06 & -.02 \\
Job control & .09 & .02 \\
Job demands & -.06 & -.03 \\
Collegial support & .12 & -.02 \\
Supervisor support & .05 & -.03 \\
Optimism & .10 & \\
\hline Indirect effects via health & & .04 \\
\hline Job insecurity & .05 & .03 \\
Personal financial difficulties & .03 & -.01 \\
Job control & -.02 & .02 \\
Job demands & .02 & -.01 \\
Collegial support & -.01 & -.01 \\
Supervisor support & -.01 & -.09 \\
Optimism & -.10 & \\
\hline
\end{tabular}

Note. All coefficients are standardized and significant at $p<.001$, except for the direct effects of personal financial difficulties and supervisor support on absenteeism which are not significant (n.s.) 


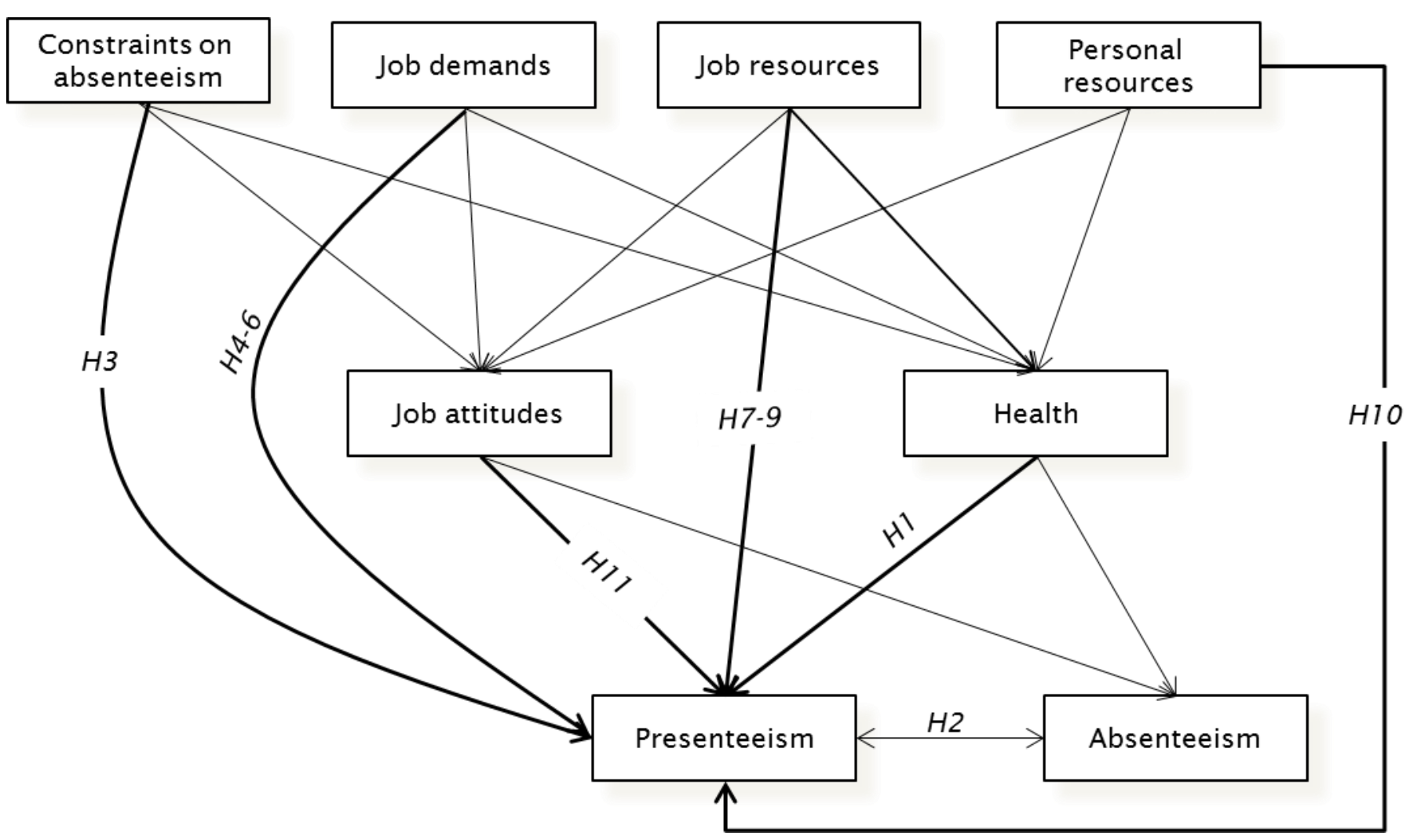

Figure 1. Conceptual model

Direct links between correlates and presenteeism are in bold. For parsimony, only the direct links to presenteeism are shown. 


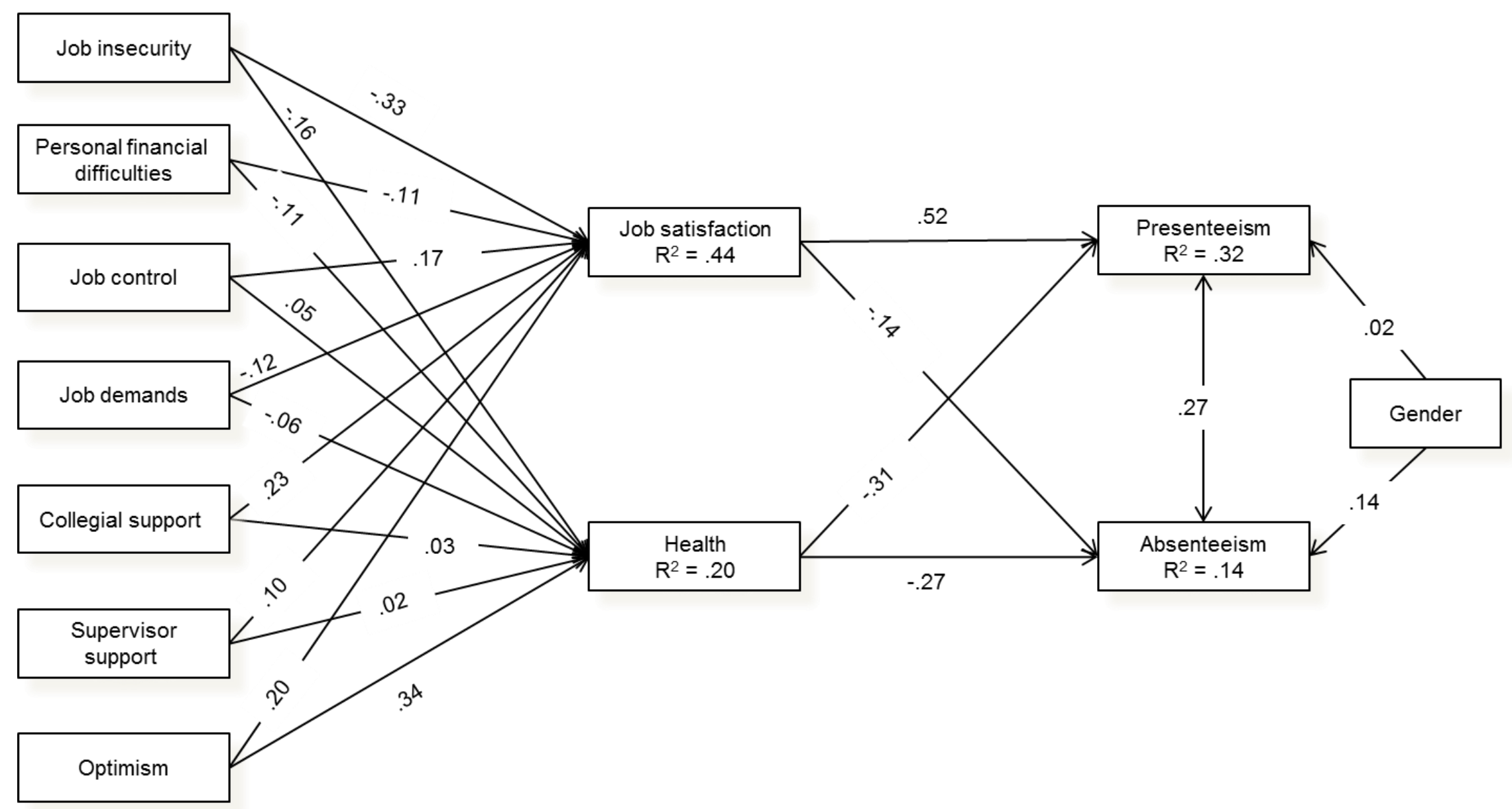

Figure 2. Parameter estimates of the structural equation model

Parameters are standardized and statistically significant at $p<.001$. For parsimony, except for gender, the direct links from the exogenous variables to presenteeism and absenteeism are omitted, and the respective parameter estimates are presented in Table 3 (see Direct effects). 